\title{
Inhibition of the MID1 protein complex: a novel approach targeting APP protein synthesis
}

\author{
Frank Matthes ${ }^{1}$, Moritz M. Hettich', Judith Schilling ${ }^{1}$, Diana Flores-Dominguez', Nelli Blank1, Thomas Wiglenda², \\ Alexander Buntru', Hanna Wolf ${ }^{2}$, Stephanie Weber ${ }^{1}$, Ina Vorberg $\mathbb{D}^{1}$, Alina Dagane ${ }^{2}$, Gunnar Dittmar ${ }^{2,3}$, Erich Wanker ${ }^{2}$, \\ Dan Ehninger ${ }^{1}$ and Sybille Krauss ${ }^{1}$
}

\begin{abstract}
Alzheimer's disease (AD) is characterized by two neuropathological hallmarks: senile plaques, which are composed of amyloid- $\beta$ (A $\beta$ ) peptides, and neurofibrillary tangles, which are composed of hyperphosphorylated tau protein. $A \beta$ peptides are derived from sequential proteolytic cleavage of the amyloid precursor protein (APP). In this study, we identified a so far unknown mode of regulation of APP protein synthesis involving the MID1 protein complex: MID1 binds to and regulates the translation of APP mRNA. The underlying mode of action of MID1 involves the mTOR pathway. Thus, inhibition of the MID1 complex reduces the APP protein level in cultures of primary neurons. Based on this, we used one compound that we discovered previously to interfere with the MID1 complex, metformin, for in vivo experiments. Indeed, long-term treatment with metformin decreased APP protein expression levels and consequently $A \beta$ in an $A D$ mouse model. Importantly, we have initiated the metformin treatment late in life, at a time-point where mice were in an already progressed state of the disease, and could observe an improved behavioral phenotype. These findings together with our previous observation, showing that inhibition of the MID1 complex by metformin also decreases tau phosphorylation, make the MID1 complex a particularly interesting drug target for treating AD.
\end{abstract}

\section{Introduction}

Alzheimer's disease (AD), the most common form of dementia in the elderly, is characterized by two neuropathological hallmarks: senile plaques, which are composed of $\mathrm{A} \beta$ peptides, and neurofibrillary tangles, which are composed of hyperphosphorylated tau protein. The disease was first described in 1907 by Alois Alzheimer ${ }^{1}$, who observed these two pathological hallmarks in patients' brains. A $\beta$ peptides are derived from sequential proteolytic cleavage of the amyloid precursor protein

Correspondence: Dan Ehninger (dan.ehninger@dzne.de) or Sybille Krauss (sybille.krauss@dzne.de)

${ }^{1}$ Deutsches Zentrum für Neurodegenerative Erkrankungen e.V., Bonn, Germany ${ }^{2}$ Max Delbrueck Center for Molecular Medicine (MDC) Berlin-Buch, Berlin, Germany

Full list of author information is available at the end of the article

Frank Matthes, Moritz M. Hettich, and Judith Schilling contributed equally to this work

Edited by A Rufini
(APP). While the non-amyloidogenic pathway involves sequential cleavage of full-length APP by the $\alpha$-secretases and $\gamma$-secretase, the amyloidogenic pathway causing the production of $A \beta$ peptides requires the cleavage of fulllength APP by the $\beta$-secretase BACE1 and the $\gamma$ secretase $^{2}$. Multiple lines of evidence suggest that overproduction of $A \beta$ results in neuronal dysfunction and, finally, in neuronal loss ${ }^{3}$. The second pathological hallmark of AD, neurofibrillary tangles, are mainly composed of hyperphosphorylated tau protein ${ }^{4,5}$. Tau is a microtubule-associated protein that stimulates and stabilizes microtubule assembly. Upon hyperphosphorylation, tau dissociates from microtubules, resulting in microtubule destabilization and neuronal death. The main tau phosphatase is protein phosphatase 2A (PP2A), 
which is capable of dephosphorylating tau at AD-relevant phospho-sites ${ }^{6}$.

As we have shown previously, the MID1-PP2A protein complex regulates the phosphorylation of tau ${ }^{7}$. MID1 acts as an E3 ubiquitin ligase and promotes the ubiquitindependent degradation of $\mathrm{PP}_{2} \mathrm{~A}^{8}$. Therefore, MID1 is a negative regulator of PP2A activity and thus inhibition of the MID1-PP2A complex is a promising approach to activate PP2A, and thereby induce its activity towards its target protein tau. In line with this, we have shown previously that the anti-diabetic drug metformin is capable of dephosphorylating tau at AD-relevant phospho-sites by interfering with the assembly of the MID1-PP2Acomplex ${ }^{7}$. Upon metformin treatment, the MID1dependent degradation of PP2Ac is inhibited, resulting in increased PP2A activity and dephosphorylation of tau at $\mathrm{AD}$ specific sites ${ }^{7}$. Besides regulating PP2A activity, MID1 also regulates the activity of the PP2A opposing kinase mTOR ${ }^{9}$. Both enzymes, PP2A and mTOR, play a crucial role in the regulation of translation initiation by the eukaryotic initiation factor (eIF) complex. In detail, in absence of mTOR, a negative regulatory protein complex containing 4E-BP1 in association with eIF4E binds to the $5^{\prime}$ end of the mRNA and inhibits translation. To activate translation mTOR phosphorylates 4E-BP1, thereby releasing its inhibitory action and allowing a heterotrimeric complex containing eIF4E, eIF4A, and eIF4G to assemble at the $5^{\prime}$ end of the mRNA. At the same time, mTOR also phosphorylates and thereby activates p70 S6 kinase (S6K). S6K in turn phosphorylates and thereby activates its downstream targets eIF4B and S6. S6 is part of the small ribosomal subunit (40S). eIF3 is a multisubunit protein that recruits $40 \mathrm{~S}$ to the mRNA. Once associated with the mRNA, 40S starts scanning towards the ATG start codon. Upon start codon recognition, the large ribosomal subunit (60S) binds and, together with
$40 \mathrm{~S}$, forms the translationally competent ribosome. The eIF complex is released from the mRNA and translation starts $^{10}$. PP2A and mTOR control translation by regulating the phosphorylation of 4E-BP1 and S6K. MID1 binds to GC-rich mRNAs and recruits its interacting proteins, including $\mathrm{S} 6 \mathrm{~K}$ and $\mathrm{S} 6^{11,12}$. By regulating the activity of both PP2A and mTOR, MID1 controls the translation of mRNAs bound to the MID1 complex ${ }^{11-14}$.

In this study we asked if MID1, besides its regulatory action on phospho-tau, could also affect APP. We show here a so far unknown connection between MID1 and APP: MID1 binds to the APP mRNA and regulates its translation. The underlying mode of action of MID1 involves the mTOR-dependent translation initiation pathway. Furthermore, we used metformin, a compound that we had shown previously to interfere with the MID1 complex and inactivate translation of MID1-target mRNAs $^{7,14,15}$, for a chronic treatment of an AD mouse model at a progressed state of disease. Our data show that metformin treatment decreases the protein levels of APP and consequently $A \beta$. This together with our previous observation that disassembly of the MID1 protein complex by metformin also decreases tau-phosphorylation ${ }^{7}$, makes the MID1 protein complex a particularly interesting drug target for treating $\mathrm{AD}$.

\section{Results}

\section{Translation of APP is regulated by MID1}

To investigate if the APP mRNA is regulated by the MID1-PP2A complex, we first tested if MID1 is able to bind to APP mRNA. For this we performed RNAimmunoprecipitations. Primary cortical neurons of wildtype mice were transfected with FLAG-MID1. After UVcrosslinking FLAG-MID1 was purified and MID1-bound mRNAs were isolated from the immunoprecipitates. As negative control an immunoprecipitation using unspecific
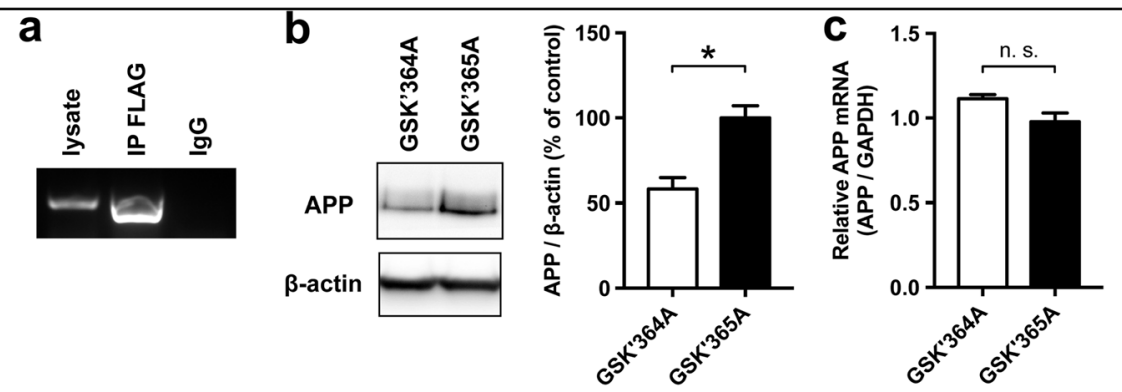

Fig. 1 APP is a MID1 target mRNA. a RNA immunoprecipitation. Primary neurons were transfected with MID1-FLAG. Afterwards MID1-mRNPs were purified by immunoprecipitation (IP FLAG) and MID1-bound mRNAs were analyzed for the presence of APP mRNA using RT-PCR. Unspecific IgG beads (lgG) were used as negative control. $5 \mu$ of the PCR product were analyzed on a 1\% agarose gel. $\mathbf{b}$ Inhibition of the MID1 complex reduces APP protein level. Primary cortical neurons were treated with a peptide that mimics the MID1-a4 binding site and thus outcompetes MID1 (GSK'364A). A mutant peptide was used as negative control (GSK'365A). APP protein levels were analyzed on western blots using APP-specific antibodies. $\beta$-actin was detected as loading control. A representative blot of $n=3$ is shown. Graphs show quantification of western blots, mean values \pm SEM. ${ }^{*} p<0.05$. c Relative APP mRNA expression was measured in cells treated as in $\mathbf{b}$ by means of real-time PCR. Columns represent mean values \pm SEM. $n=3$. APP amyloid precursor protein 
IgGs was performed. RT-PCRs clearly showed the presence of APP mRNA in the MID1-immunoprecipitates (Fig. 1a).

In previous studies we showed that binding of the MID1-complex to its target mRNAs induces protein translation from the respective mRNA ${ }^{12,15,16}$. Therefore, we asked if the observed binding between APP mRNA and MID1 leads to an induction of APP translation. To test this we performed an experiment in primary cortical neurons with a peptide that mimics the binding sequence between MID1 and the $\alpha 4-\mathrm{PP} 2 \mathrm{~A}$ complex and therefore specifically outcompetes MID1. Depletion of MID1 led to a significant reduction of APP protein as shown on a western blot (Fig. 1b). Of note, the mRNA level of APP did not change significantly (Fig. 1c), which is in line with an inhibition at the protein synthesis level.

\section{MID1 regulates APP translation by interacting with the mTOR-dependent translation initiation pathway}

As we have shown previously, the MID1-complex regulates translation in concert with mTOR. To identify at which exact step of the mTOR-dependent translation initiation MID1 functions, we analyzed proteins that bind to MID1. For this we performed an immunoprecipitation of FLAG-MID1 and analyzed all MID1-bound proteins by mass spectrometry. As expected, we detected several members of the mTOR-translation initiation cascade (Fig. 2a and Table 1), several of which we validated on a western blot of FLAG-MID1-immunoprecipitates using specific antibodies (Fig. 2b). Interestingly, all MID1bound proteins identified here were proteins of the mTOR-dependent translation pathway that act downstream of mTOR as well as $\mathrm{S} 6 \mathrm{~K}$ and $4 \mathrm{E}-\mathrm{BP}$, suggesting that MID1 regulates the mTOR-dependent translation by acting on either the eIFs or the ribosome. Thus, in a second set of experiments we added EDTA during the coimmunoprecipitation. EDTA dissociates ribosomal particles ${ }^{17}$. While binding of most of the identified proteins to MID1 was abolished by the treatment, RPLP0, a member of the large subunit of the ribosome remained attached to MID1 (Fig. 2c). Since all of the proteins identified by mass spectrometry bind RNA in general, their presence in the MID1-immunoprecipitate may be explained by RNAmediated indirect binding rather than by direct proteinprotein interaction. To test which of the identified proteins bind to MID1 independent of RNA, we performed co-immunoprecipitation experiments in the presence or absence of RNase. Binding of the identified eIF proteins to MID1 was abolished by RNase treatment, while RPLP0, RPL5, and RPS3 remained attached to MID1 (Fig. 2d). These data suggest that MID1 directly binds to the ribosome to stimulate mTOR-dependent translation. In line with a MID1-mTOR dependent translation of APP, application of an mTOR inhibitor reduced APP translation both in an in vitro translation assay (Fig. 2e) as well as in primary neurons (Fig. 2f).

\section{Metformin reduces APP protein and APP cleavage products}

To target MID1 we decided to use metformin, a compound that we had shown previously to interfere with the MID1 complex and inactivate translation of MID1-target mRNAs $^{7,14,15}$. In line with what we have observed for other MID1-target mRNAs, metformin treatment of primary cortical neurons also led to a reduction of APP protein in a dose-dependent manner (Fig. 3a).

Finally, to investigate this effect in vivo, we chronically treated transgenic APP/PS1 mice with $5 \mathrm{~g} / \mathrm{l}$ metformin in the drinking water for 8 months. In line with our data from primary neurons, full-length APP protein was significantly reduced in metformin treated mice (Fig. 4a), while APP mRNA levels were not significantly changed after metformin treatment (Fig. 4b). Together, these data suggest that the APP protein level was decreased in vivo on the translational level, which can be explained by inhibition of the MID1 complex. In line with an mTORMID1-PP2A-dependent down-regulation of APP in these mice, the phosphorylation of S6 was significantly reduced in brain lysates of these mice, as determined by western blots (Fig. 4c).

A reduction of APP should lead to a reduced $A \beta$ plaque burden in the treated animals. To quantify this we first measured levels of $A \beta$ on dot blots, showing that $A \beta$ levels were significantly decreased in metformin treated animals (Fig. 5a). Second, in an ELISA measuring the levels of $A \beta 40$ and $A \beta 42$, a significant decrease of $A \beta$ peptides was observed in both female and male mice (Fig. 5b). Of note, there was also a significant difference in $A \beta$ levels between female and male mice. To investigate the $A \beta$ plaque burden in the hippocampus, we performed Thioflavin-S stainings. In line with dot blot and ELISA experiments, thioflavin staining showed less aggregates in metformin treated animals (Fig. 5c). To test if metformin affects learning and memory, APP/PS1 mice that were treated with metformin were examined in behavioral tests. A significantly improved performance in the Morris water maze was observed in animals that were treated with metformin (Fig. 5d).

Besides regulating translation, mTOR is also a known regulator of autophagy. Therefore, in our in vivo set-up we cannot rule out that the observed reduction of $A \beta$ could be at least partially due to increased clearance via autophagy. To address this, we analyzed the degradation of $A \beta$ in SH-EP cells containing TAMRA-A $\beta 42$ aggregates. Clearly, no increased degradation of $A \beta$ was detectable in these cells, suggesting that metformin treatment does not induce autophageal degradation of $\mathrm{A} \beta$ (Fig. 6). 
a

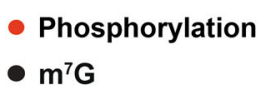

- $\mathrm{m}^{\mathrm{T}} \mathrm{C}$

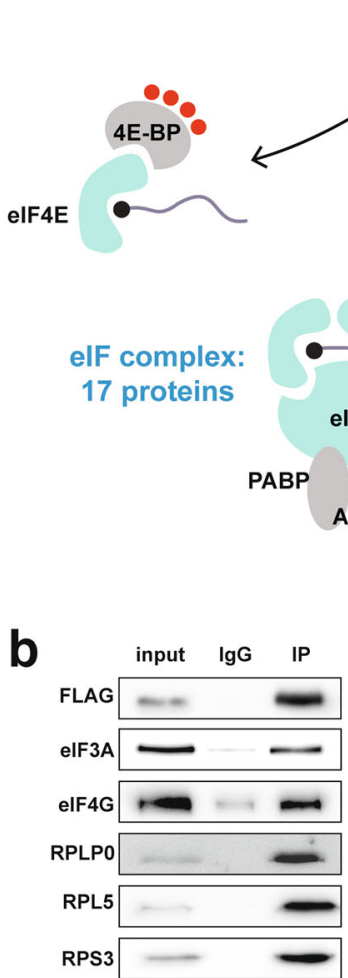

e

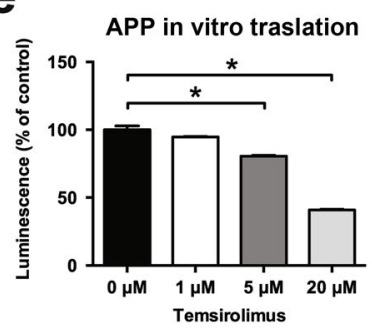

Translation ON

mTOR
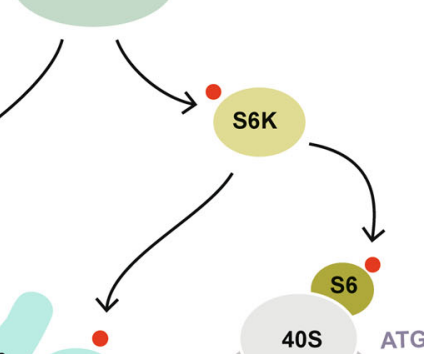

elF3 elF4B elF4A IF4G

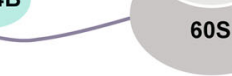

$60 S$

ribosome: 80 proteins
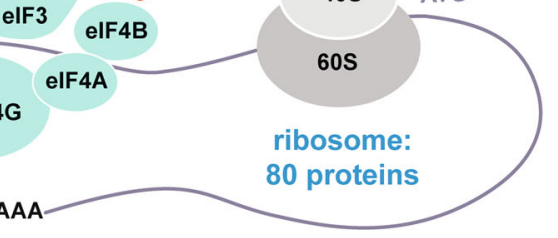

C

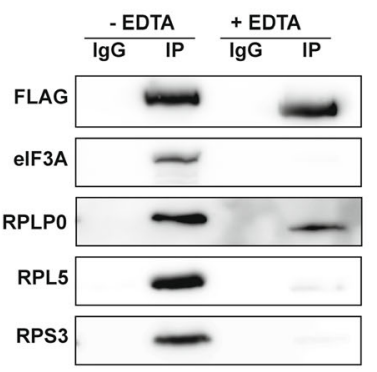

f

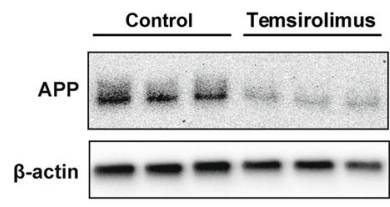

Translation OFF
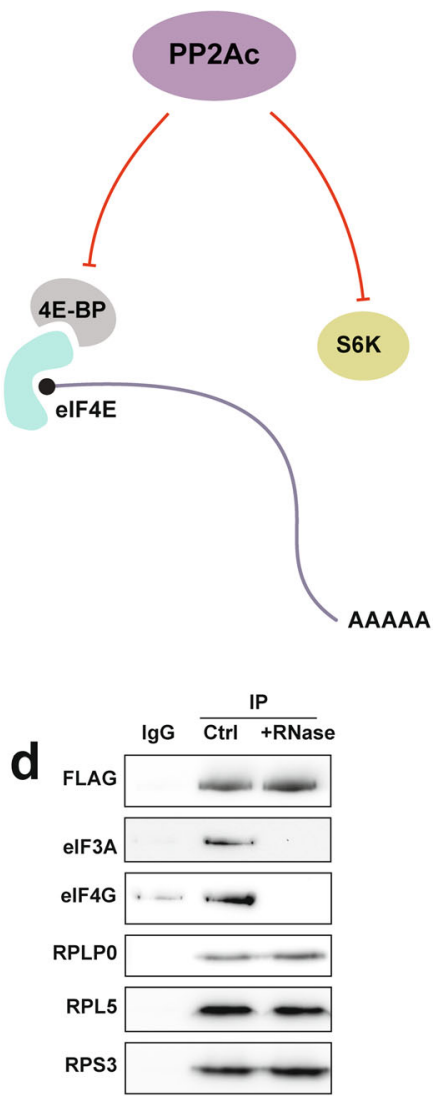

Fig. 2 MID1 is connected to the mTOR-dependent translation initiation pathway. a Identification of the MID1-interactome. MID1-FLAG waS expressed in HEK293T cells and MID1-complexes were purified by immunoprecipitation. MID1-binding proteins were identified by mass spectrometry. The mTOR-dependent translation initiation pathway is shown and the number of proteins identified belonging either to the eukaryotic translation initiation factor complex (elF complex) or the ribosome are indicated. $\mathbf{b}$ Validation of the mass spectrometry results shown in a and Table 1. MID1-FLAG was expressed in HEK293T cells and MID1-complexes were purified by immunoprecipitation (IP FLAG). As negative control, unspecific $\lg G$ agarose beads were used (IgG). Immunoprecipitates were analyzed on western blots using specific antibodies to detect MID1-FLAG, elF3A, elF4G, RPLP0, RPL5, RPS3. c Effect of ribosome disassembly on the composition of the MID1-complex. MID1-FLAG was expressed in HEK293T cells and immunopurified (IP FLAG) in the presence or absence of high concentrations of EDTA. Immunoprecipitates were analyzed on western blots using specific antibodies for MID1-FLAG, elF3A, RPLP0, RPL5, RPS3. $\mathbf{d}$ To analyze the MID1-complex composition and its dependency on RNA, MID1-FLAG was expressed in HEK293T cells and immunopurified (IP FLAG) in the presence or absence of RNAse. As negative control, unspecific IgG agarose beads were used (IgG). Immunoprecipitates were analyzed on western blots using specific antibodies for MID1-FLAG, elF3A, elF4G, RPLPO, RPL5, RPS3. e, $\mathbf{f}$ mTOR regulates translation of APP. e In vitro translation of in vitro transcribed APP-mRNA tagged to luciferase in the presence or absence of the mTOR-inhibitor temsirolimus. The level of translated luciferase reporter was measured in a luciferase assay. Columns represent mean values \pm SEM. $n=3 .{ }^{*} p<0.01$. f Primary neurons were treated with the mTOR-inhibitor temsirolimus. Protein extracts were analyzed on western blots, detecting APP and $\beta$-actin as loading control. Graph shows quantification of western blots, mean values \pm SEM. $n=3 .{ }^{*} p<0.01$. APP amyloid precursor protein 
Table 1 Statistical analysis of proteins identified mass spectrometry analysis of MID1 immunoprecipitates

\begin{tabular}{|c|c|c|c|}
\hline Protein name & Gene ID & Log2 ratio & $P$-value \\
\hline ATP-binding cassette sub-family D member 3 & ABCD3 & $2.75 \mathrm{E}+01$ & 2.04E-03 \\
\hline ATP-binding cassette sub-family $\mathrm{F}$ member 2 & ABCF2 & $2.88 \mathrm{E}+01$ & 5.96E-04 \\
\hline Apoptotic chromatin condensation inducer in the nucleus & ACIN1 & $2.72 \mathrm{E}+01$ & $1.39 \mathrm{E}-02$ \\
\hline Aldehyde dehydrogenase $X$, mitochondrial & ALDH1B1 & $2.62 \mathrm{E}+01$ & 3.61E-04 \\
\hline Mitochondrial 10-formyltetrahydrofolate dehydrogenase & ALDH1L2 & $2.66 \mathrm{E}+01$ & 1.97E-02 \\
\hline THO complex subunit 4 & ALYREF & $2.99 \mathrm{E}+01$ & 7.55E-04 \\
\hline Serine/threonine-protein phosphatase 6 reg. ankyrin repeat subunit A & ANKRD28 & $2.63 \mathrm{E}+01$ & $1.85 \mathrm{E}-02$ \\
\hline Coatomer subunit delta & ARCN1 & $2.65 \mathrm{E}+01$ & 2.36E-02 \\
\hline Activating signal cointegrator 1 complex subunit 3 & ASCC3 & $2.59 \mathrm{E}+01$ & 7.96E-03 \\
\hline ATPase family AAA domain-containing protein $3 \mathrm{~A}$ & ATAD3A & 1.77E+00 & $3.98 \mathrm{E}-02$ \\
\hline Sodium/potassium-transporting ATPase subunit alpha-1 & ATP1A1 & $2.72 \mathrm{E}+01$ & 4.39E-04 \\
\hline Ribosome biogenesis protein BMS1 homolog & BMS1 & $2.90 \mathrm{E}+01$ & $8.92 \mathrm{E}-03$ \\
\hline Ribosome biogenesis protein BRX1 homolog & BRIX1 & $2.68 \mathrm{E}+01$ & $1.41 \mathrm{E}-02$ \\
\hline Caprin-1 & CAPRIN1 & $2.80 \mathrm{E}+01$ & $5.88 \mathrm{E}-03$ \\
\hline Coiled-coil domain-containing protein 124 & CCDC124 & $2.94 \mathrm{E}+01$ & $1.91 \mathrm{E}-04$ \\
\hline T-complex protein 1 subunit gamma & ССТ3 & $2.63 \mathrm{E}+01$ & 4.86E-02 \\
\hline T-complex protein 1 subunit epsilon & CCT5 & $2.64 \mathrm{E}+01$ & $1.42 \mathrm{E}-03$ \\
\hline Cell division cycle 5 -like protein & CDC5L & $3.04 \mathrm{E}+01$ & $3.51 \mathrm{E}-03$ \\
\hline Centrosomal protein of $170 \mathrm{kDa}$ & CEP170 & $2.71 \mathrm{E}+01$ & $2.53 \mathrm{E}-03$ \\
\hline Chromatin target of PRMT1 protein & CHTOP & $2.81 \mathrm{E}+01$ & 3.45E-02 \\
\hline CLIP-associating protein 2 & CLASP2 & $2.74 \mathrm{E}+01$ & 4.83E-03 \\
\hline Methylosome subunit plCln & CLNS1A & 2.97E+01 & 2.16E-03 \\
\hline Coatomer subunit gamma-2 & COPG2 & $2.59 \mathrm{E}+01$ & 2.98E-04 \\
\hline Coronin-1C & CORO1C & $3.03 \mathrm{E}+01$ & 2.00E-02 \\
\hline Cleavage and polyadenylation specificity factor subunit 6 & CPSF6 & $2.93 \mathrm{E}+01$ & 4.13E-03 \\
\hline Cleavage and polyadenylation specificity factor subunit 7 & CPSF7 & $2.73 \mathrm{E}+01$ & $2.20 \mathrm{E}-03$ \\
\hline Probable ATP-dependent RNA helicase DDX17 & DDX17 & $3.22 \mathrm{E}+01$ & $1.28 \mathrm{E}-02$ \\
\hline Probable ATP-dependent RNA helicase DDX20 & DDX20 & $2.73 \mathrm{E}+01$ & 2.81E-02 \\
\hline Nucleolar RNA helicase 2 & DDX21 & $3.01 \mathrm{E}+01$ & $8.42 \mathrm{E}-03$ \\
\hline Probable ATP-dependent RNA helicase DDX23 & DDX23 & $2.93 \mathrm{E}+01$ & 4.58E-03 \\
\hline ATP-dependent RNA helicase DDX3X & DDX3X & $2.66 \mathrm{E}+01$ & $5.42 \mathrm{E}-04$ \\
\hline Probable ATP-dependent RNA helicase DDX41 & DDX41 & $2.73 \mathrm{E}+01$ & 4.88E-03 \\
\hline Probable ATP-dependent RNA helicase DDX5 & DDX5 & $2.97 \mathrm{E}+01$ & $1.38 \mathrm{E}-02$ \\
\hline ATP-dependent RNA helicase DDX50 & DDX50 & $2.65 \mathrm{E}+01$ & $5.75 \mathrm{E}-03$ \\
\hline Putative pre-mRNA-splicing factor ATP-dependent RNA helicase DHX15 & $\mathrm{DHX15}$ & $2.76 \mathrm{E}+01$ & 6.67E-03 \\
\hline Putative ATP-dependent RNA helicase DHX30 & $\mathrm{DHX30}$ & $2.99 \mathrm{E}+01$ & $1.03 \mathrm{E}-02$ \\
\hline ATP-dependent RNA helicase A & DHX9 & $7.63 \mathrm{E}+00$ & 4.50E-03 \\
\hline Elongation factor 2 & EEF2 & $4.68 \mathrm{E}+00$ & $8.14 \mathrm{E}-03$ \\
\hline 116 kDa U5 small nuclear ribonucleoprotein component & EFTUD2 & $3.04 \mathrm{E}+01$ & $6.54 \mathrm{E}-03$ \\
\hline
\end{tabular}


Table 1 continued

\begin{tabular}{|c|c|c|c|}
\hline Protein name & Gene ID & Log2 ratio & $P$-value \\
\hline Eukaryotic translation initiation factor 3 subunit A & EIF3A & $3.34 \mathrm{E}+01$ & $2.89 \mathrm{E}-04$ \\
\hline Eukaryotic translation initiation factor 3 subunit B & EIF3B & $3.19 \mathrm{E}+01$ & $6.22 \mathrm{E}-03$ \\
\hline Eukaryotic translation initiation factor 3 subunit $C$ & EIF3C & $3.23 \mathrm{E}+01$ & 1.43E-03 \\
\hline Eukaryotic translation initiation factor 3 subunit D & EIF3D & $3.01 \mathrm{E}+01$ & $1.72 \mathrm{E}-03$ \\
\hline Eukaryotic translation initiation factor 3 subunit $\mathrm{E}$ & EIF3E & $3.15 \mathrm{E}+01$ & $2.60 \mathrm{E}-03$ \\
\hline Eukaryotic translation initiation factor 3 subunit $F$ & EIF3F & $3.08 \mathrm{E}+01$ & $9.00 \mathrm{E}-03$ \\
\hline Eukaryotic translation initiation factor 3 subunit $G$ & EIF3G & $2.99 \mathrm{E}+01$ & 1.64E-04 \\
\hline Eukaryotic translation initiation factor 3 subunit I & ElF3| & $3.07 \mathrm{E}+01$ & 4.95E-03 \\
\hline Eukaryotic translation initiation factor 3 subunit J & EIF3J & $2.75 \mathrm{E}+01$ & 2.97E-04 \\
\hline Eukaryotic translation initiation factor 3 subunit $\mathrm{K}$ & EIF3K & $2.75 \mathrm{E}+01$ & 4.35E-02 \\
\hline Eukaryotic translation initiation factor 3 subunit $\mathrm{L}$ & EIF3L & $3.20 \mathrm{E}+01$ & $1.62 \mathrm{E}-03$ \\
\hline Eukaryotic translation initiation factor 3 subunit M & EIF3M & $3.06 \mathrm{E}+01$ & $2.52 \mathrm{E}-02$ \\
\hline Eukaryotic translation initiation factor 3 subunit $\mathrm{H}$ & EIF3S3 & $2.98 \mathrm{E}+01$ & 4.34E-03 \\
\hline Eukaryotic initiation factor $4 \mathrm{~A}-\mathrm{I}$ & EIF4A1 & $2.82 \mathrm{E}+01$ & $1.28 \mathrm{E}-02$ \\
\hline Eukaryotic initiation factor $4 \mathrm{~A}-1 \|$ & EIF4A3 & $2.66 \mathrm{E}+01$ & 2.37E-02 \\
\hline Eukaryotic translation initiation factor $4 \mathrm{~B}$ & EIF4B & $3.07 E+01$ & 1.05E-02 \\
\hline Eukaryotic translation initiation factor 6 & EIF6 & $2.71 \mathrm{E}+01$ & 1.74E-02 \\
\hline Emerin & EMD & $2.73 \mathrm{E}+01$ & 1.99E-02 \\
\hline Erlin-2 & ERLIN2 & $2.81 \mathrm{E}+01$ & 7.54E-03 \\
\hline Exosome component 10 & EXOSC10 & $2.76 \mathrm{E}+01$ & 3.45E-03 \\
\hline Exosome complex component RRP45 & EXOSC9 & $2.59 \mathrm{E}+01$ & 2.53E-02 \\
\hline Constitutive coactivator of PPAR-gamma-like protein 1 & FAM120A & $2.74 \mathrm{E}+01$ & 1.36E-02 \\
\hline Phenylalanine--tRNA ligase alpha subunit & FARSA & $2.78 \mathrm{E}+01$ & 7.54E-03 \\
\hline Phenylalanine--tRNA ligase beta subunit & FARSB & $2.78 \mathrm{E}+01$ & 1.17E-02 \\
\hline $40 \mathrm{~S}$ ribosomal protein $\mathbf{S 3 0}$ & FAU & $2.85 E+01$ & $2.31 \mathrm{E}-03$ \\
\hline Protein furry homolog-like & FRYL & $3.02 E+01$ & 2.54E-02 \\
\hline Gem-associated protein 4 & GEMIN4 & $2.71 E+01$ & 2.53E-03 \\
\hline Guanine nucleotide-binding protein subunit beta-2-like 1 & GNB2L1 & $3.25 \mathrm{E}+01$ & 3.47E-04 \\
\hline Nucleolar GTP-binding protein 2 & GNL2 & $2.75 \mathrm{E}+01$ & 7.11E-03 \\
\hline Guanine nucleotide-binding protein-like 3 & GNL3 & $2.69 \mathrm{E}+01$ & 4.03E-04 \\
\hline Golgin subfamily A member 3 & GOLGA3 & $2.93 E+01$ & 3.96E-03 \\
\hline General transcription factor $3 C$ polypeptide 2 & GTF3C2 & $2.75 E+01$ & 3.97E-03 \\
\hline General transcription factor $3 C$ polypeptide 3 & GTF3C3 & $2.57 E+01$ & $3.56 \mathrm{E}-02$ \\
\hline General transcription factor $3 C$ polypeptide 4 & GTF3C4 & $2.70 \mathrm{E}+01$ & $2.46 \mathrm{E}-03$ \\
\hline Nucleolar GTP-binding protein 1 & GTPBP4 & $2.87 \mathrm{E}+01$ & $1.26 \mathrm{E}-02$ \\
\hline Histone $\mathrm{H} 2 \mathrm{~B}$ & HIST1H2BN & $2.99 \mathrm{E}+01$ & $1.62 \mathrm{E}-02$ \\
\hline Heterogeneous nuclear ribonucleoproteins C1/C2 & HNRNPC & $3.08 \mathrm{E}+01$ & $3.22 \mathrm{E}-04$ \\
\hline Heterogeneous nuclear ribonucleoprotein D0 & HNRNPD & $2.60 \mathrm{E}+01$ & 2.60E-02 \\
\hline Heterogeneous nuclear ribonucleoprotein F & HNRNPF & $2.74 \mathrm{E}+01$ & 4.67E-03 \\
\hline Heterogeneous nuclear ribonucleoprotein $\mathrm{K}$ & HNRNPK & $2.96 \mathrm{E}+01$ & 9.43E-04 \\
\hline
\end{tabular}


Table 1 continued

\begin{tabular}{|c|c|c|c|}
\hline Protein name & Gene ID & Log2 ratio & $P$-value \\
\hline Heterogeneous nuclear ribonucleoprotein M & HNRNPM & $6.56 \mathrm{E}+00$ & $1.98 \mathrm{E}-02$ \\
\hline Heterogeneous nuclear ribonucleoprotein $\mathrm{R}$ & HNRNPR & $2.99 \mathrm{E}+01$ & 4.29E-03 \\
\hline Heterogeneous nuclear ribonucleoprotein $U$ & HNRNPU & $3.23 \mathrm{E}+01$ & $2.34 \mathrm{E}-03$ \\
\hline Isoleucine--tRNA ligase, cytoplasmic & IARS & $2.72 \mathrm{E}+01$ & $3.12 \mathrm{E}-03$ \\
\hline Insulin-like growth factor 2 mRNA-binding protein 1 & |GF2BP1 & $3.18 \mathrm{E}+01$ & 1.09E-03 \\
\hline Insulin-like growth factor 2 mRNA-binding protein 3 & IGF2BP3 & $2.81 \mathrm{E}+01$ & $1.22 \mathrm{E}-02$ \\
\hline Interleukin enhancer-binding factor 2 & ILF2 & $3.10 \mathrm{E}+01$ & $1.08 \mathrm{E}-02$ \\
\hline Interleukin enhancer-binding factor 3 & ILF3 & $3.27 \mathrm{E}+01$ & $2.99 \mathrm{E}-03$ \\
\hline Importin-8 & IPO8 & $2.74 \mathrm{E}+01$ & $1.30 \mathrm{E}-02$ \\
\hline Insulin receptor substrate 4 & IRS4 & $1.33 \mathrm{E}+00$ & $3.38 \mathrm{E}-03$ \\
\hline Influenza virus NS1A-binding protein & IVNS1ABP & $3.33 \mathrm{E}+01$ & 3.05E-03 \\
\hline Tyrosine-protein kinase JAK1 & JAK1 & $2.88 \mathrm{E}+01$ & 4.64E-03 \\
\hline BTB/POZ domain-containing protein KCTD17 & KCTD17 & $2.96 \mathrm{E}+01$ & $1.23 \mathrm{E}-02$ \\
\hline BTB/POZ domain-containing protein KCTD5 & KCTD5 & $2.96 \mathrm{E}+01$ & 3.67E-04 \\
\hline Kinesin-like protein KIF11 & KIF11 & $1.48 \mathrm{E}+00$ & $1.25 \mathrm{E}-03$ \\
\hline La-related protein 1 & LARP1 & $3.17 \mathrm{E}+01$ & 9.37E-04 \\
\hline La-related protein 4 & LARP4 & $2.86 \mathrm{E}+01$ & 7.22E-03 \\
\hline La-related protein $4 \mathrm{~B}$ & LARP4B & $2.65 E+01$ & $8.21 \mathrm{E}-03$ \\
\hline LIM domain and actin-binding protein 1 & LIMA1 & $2.98 \mathrm{E}+01$ & 7.34E-03 \\
\hline Leucine-rich PPR motif-containing protein, mitochondrial & LRPPRC & $2.63 \mathrm{E}+01$ & $8.82 \mathrm{E}-03$ \\
\hline Putative RNA-binding protein Luc7-like 2 & LUC7L2 & $3.00 E+01$ & $3.39 \mathrm{E}-03$ \\
\hline Luc7-like protein 3 & LUC7L3 & $2.81 \mathrm{E}+01$ & $5.20 \mathrm{E}-03$ \\
\hline Microtubule-associated protein 1B & MAP1B & $3.01 \mathrm{E}+01$ & $3.76 \mathrm{E}-03$ \\
\hline Serine/threonine-protein kinase MARK2 & MARK2 & $2.60 \mathrm{E}+01$ & $3.76 \mathrm{E}-03$ \\
\hline Methionine--tRNA ligase, cytoplasmic & MARS & $2.62 \mathrm{E}+01$ & $1.62 \mathrm{E}-03$ \\
\hline Matrin-3 & MATR3 & $2.87 \mathrm{E}+01$ & $1.32 \mathrm{E}-03$ \\
\hline DNA replication licensing factor MCM7 & MCM7 & $2.83 \mathrm{E}+01$ & 8.19E-03 \\
\hline E3 ubiquitin-protein ligase Midline-1 & MID1 & $3.76 \mathrm{E}+01$ & $3.26 \mathrm{E}-04$ \\
\hline Putative helicase MOV-10 & MOV10 & $2.77 \mathrm{E}+01$ & 2.49E-02 \\
\hline $28 \mathrm{~S}$ ribosomal protein S17, mitochondrial & MRPS17 & $2.91 E+01$ & $6.96 \mathrm{E}-03$ \\
\hline $28 \mathrm{~S}$ ribosomal protein $\mathrm{S} 22$, mitochondrial & MRPS22 & $2.74 \mathrm{E}+01$ & 4.69E-03 \\
\hline $28 \mathrm{~S}$ ribosomal protein $\mathbf{S} 25$, mitochondrial & MRPS25 & $2.71 \mathrm{E}+01$ & $1.14 \mathrm{E}-02$ \\
\hline 28 S ribosomal protein S27, mitochondrial & MRPS27 & $2.64 \mathrm{E}+01$ & $3.48 \mathrm{E}-02$ \\
\hline Protein LYRIC & MTDH & $2.72 \mathrm{E}+01$ & $1.03 \mathrm{E}-02$ \\
\hline Myb-binding protein $1 \mathrm{~A}$ & MYBBP1A & $2.90 \mathrm{E}+01$ & 1.44E-04 \\
\hline Myosin-10 & MYH10 & $1.13 \mathrm{E}+00$ & $2.28 \mathrm{E}-02$ \\
\hline Myosin-9 & MYH9 & $2.92 \mathrm{E}+01$ & 4.78E-03 \\
\hline Unconventional myosin-lb & MYO1B & $2.71 \mathrm{E}+01$ & $2.88 \mathrm{E}-02$ \\
\hline Nicotinamide phosphoribosyltransferase & NAMPT & $2.75 \mathrm{E}+01$ & $8.55 \mathrm{E}-03$ \\
\hline Nucleosome assembly protein 1-like 1 & NAP1L1 & 2.57E+01 & 7.18E-03 \\
\hline
\end{tabular}


Table 1 continued

\begin{tabular}{|c|c|c|c|}
\hline Protein name & Gene ID & Log2 ratio & $P$-value \\
\hline Nuclear cap-binding protein subunit 1 & NCBP1 & $2.81 E+01$ & 4.89E-04 \\
\hline Nucleolin & $\mathrm{NCL}$ & $2.86 \mathrm{E}+01$ & $6.74 \mathrm{E}-03$ \\
\hline Nucleolar complex protein 4 homolog & NOC4L & $2.80 \mathrm{E}+01$ & 8.27E-03 \\
\hline Probable $28 \mathrm{~S}$ rRNA (cytosine(4447)-C(5))-methyltransferase & NOP2 & $2.62 \mathrm{E}+01$ & $5.08 \mathrm{E}-03$ \\
\hline Cleavage and polyadenylation specificity factor subunit 5 & NUDT21 & $2.96 \mathrm{E}+01$ & $6.21 \mathrm{E}-04$ \\
\hline OTU domain-containing protein 4 & OTUD4 & $2.74 \mathrm{E}+01$ & $1.45 \mathrm{E}-03$ \\
\hline Prolyl 4-hydroxylase subunit alpha-1 & P4HA1 & $2.79 \mathrm{E}+01$ & 4.44E-03 \\
\hline Proliferation-associated protein 2G4 & PA2G4 & $3.08 \mathrm{E}+01$ & 7.55E-03 \\
\hline Polyadenylate-binding protein 1 & PABPC1 & $3.23 \mathrm{E}+01$ & 2.17E-03 \\
\hline Polyadenylate-binding protein 4 & PABPC4 & $3.22 \mathrm{E}+01$ & $2.78 \mathrm{E}-03$ \\
\hline Programmed cell death protein 4 & PDCD4 & $2.94 \mathrm{E}+01$ & 8.37E-03 \\
\hline Proline-, glutamic acid- and leucine-rich protein 1 & PELP1 & $2.66 \mathrm{E}+01$ & $9.09 \mathrm{E}-03$ \\
\hline Serine/threonine-protein phosphatase PGAM5, mitochondrial & PGAM5 & $2.86 \mathrm{E}+01$ & $3.52 \mathrm{E}-03$ \\
\hline Protein arginine $\mathrm{N}$-methyltransferase 5 & PRMT5 & $3.54 \mathrm{E}+01$ & $6.16 \mathrm{E}-04$ \\
\hline Pre-mRNA-processing factor 19 & PRPF19 & $3.02 \mathrm{E}+01$ & 3.67E-03 \\
\hline U4/U6 small nuclear ribonucleoprotein Prp3 & PRPF3 & $2.70 \mathrm{E}+01$ & 1.69E-02 \\
\hline U4/U6 small nuclear ribonucleoprotein Prp31 & PRPF31 & $2.97 \mathrm{E}+01$ & 8.19E-04 \\
\hline U4/U6 small nuclear ribonucleoprotein Prp4 & PRPF4 & $2.64 \mathrm{E}+01$ & 3.83E-03 \\
\hline Pre-mRNA-processing factor 6 & PRPF6 & $2.98 \mathrm{E}+01$ & $6.12 \mathrm{E}-03$ \\
\hline Pre-mRNA-processing-splicing factor 8 & PRPF8 & $3.11 \mathrm{E}+01$ & 3.06E-03 \\
\hline Ribose-phosphate pyrophosphokinase 1 & PRPS1 & $5.58 \mathrm{E}+00$ & $3.60 \mathrm{E}-03$ \\
\hline Ribose-phosphate pyrophosphokinase 2 & PRPS2 & $2.93 \mathrm{E}+01$ & 1.56E-02 \\
\hline Phosphoribosyl pyrophosphate synthase-associated protein 1 & PRPSAP1 & $3.05 \mathrm{E}+01$ & $8.50 \mathrm{E}-03$ \\
\hline Phosphoribosyl pyrophosphate synthase-associated protein 2 & PRPSAP2 & $3.25 \mathrm{E}+01$ & 2.15E-04 \\
\hline Protein PRRC2A & PRRC2A & $2.85 E+01$ & $8.43 \mathrm{E}-03$ \\
\hline Protein PRRC2C & PRRC2C & $2.97 \mathrm{E}+01$ & 2.05E-02 \\
\hline 265 protease regulatory subunit 4 & PSMC1 & $2.97 \mathrm{E}+01$ & $5.78 \mathrm{E}-03$ \\
\hline 265 protease regulatory subunit 7 & PSMC2 & $3.07 E+01$ & $8.06 \mathrm{E}-04$ \\
\hline $26 \mathrm{~S}$ protease regulatory subunit $6 \mathrm{~A}$ & PSMC3 & $2.89 E+01$ & $5.50 \mathrm{E}-03$ \\
\hline 265 protease regulatory subunit $6 \mathrm{~B}$ & PSMC4 & $1.19 \mathrm{E}+00$ & $1.54 \mathrm{E}-02$ \\
\hline 265 protease regulatory subunit 8 & PSMC5 & 4.55E+00 & $3.71 \mathrm{E}-04$ \\
\hline $26 \mathrm{~S}$ protease regulatory subunit $10 \mathrm{~B}$ & PSMC6 & $2.84 \mathrm{E}+01$ & $1.52 \mathrm{E}-03$ \\
\hline 265 proteasome non-ATPase regulatory subunit 1 & PSMD1 & $2.97 \mathrm{E}+01$ & $2.12 \mathrm{E}-03$ \\
\hline 265 proteasome non-ATPase regulatory subunit 10 & PSMD10 & $2.85 \mathrm{E}+01$ & $2.02 \mathrm{E}-02$ \\
\hline $26 \mathrm{~S}$ proteasome non-ATPase regulatory subunit 11 & PSMD11 & $3.02 E+01$ & $1.94 \mathrm{E}-02$ \\
\hline 265 proteasome non-ATPase regulatory subunit 12 & PSMD12 & $2.90 \mathrm{E}+01$ & 4.18E-03 \\
\hline 265 proteasome non-ATPase regulatory subunit 13 & PSMD13 & $2.95 \mathrm{E}+01$ & $3.11 \mathrm{E}-03$ \\
\hline 265 proteasome non-ATPase regulatory subunit 14 & PSMD14 & $2.80 \mathrm{E}+01$ & $1.85 \mathrm{E}-03$ \\
\hline 265 proteasome non-ATPase regulatory subunit 2 & PSMD2 & $2.15 \mathrm{E}+00$ & $4.38 \mathrm{E}-03$ \\
\hline $26 \mathrm{~S}$ proteasome non-ATPase regulatory subunit 3 & PSMD3 & $3.04 \mathrm{E}+01$ & $1.48 \mathrm{E}-04$ \\
\hline
\end{tabular}


Table 1 continued

\begin{tabular}{|c|c|c|c|}
\hline Protein name & Gene ID & Log2 ratio & $P$-value \\
\hline 265 proteasome non-ATPase regulatory subunit 4 & PSMD4 & $2.79 \mathrm{E}+01$ & 1.70E-04 \\
\hline 265 proteasome non-ATPase regulatory subunit 6 & PSMD6 & $2.96 \mathrm{E}+01$ & $9.65 \mathrm{E}-03$ \\
\hline 265 proteasome non-ATPase regulatory subunit 7 & PSMD7 & $3.75 E+00$ & 1.13E-02 \\
\hline 265 proteasome non-ATPase regulatory subunit 8 & PSMD8 & $2.75 \mathrm{E}+01$ & $1.56 \mathrm{E}-03$ \\
\hline Poly(U)-binding-splicing factor PUF60 & PUF60 & $2.75 E+01$ & 9.95E-04 \\
\hline Pyrroline-5-carboxylate reductase & PYCR1 & $2.55 \mathrm{E}+01$ & $3.49 \mathrm{E}-03$ \\
\hline RNA-binding protein 10 & RBM10 & $3.30 \mathrm{E}+01$ & 4.88E-04 \\
\hline RNA-binding protein 14 & RBM14 & $2.94 \mathrm{E}+01$ & $6.57 \mathrm{E}-03$ \\
\hline RNA-binding protein 25 & RBM25 & $2.75 E+01$ & 7.71E-03 \\
\hline RNA-binding protein 26 & RBM26 & $2.63 \mathrm{E}+01$ & $3.79 \mathrm{E}-02$ \\
\hline RNA-binding protein 27 & RBM27 & $2.70 E+01$ & $1.20 \mathrm{E}-02$ \\
\hline RNA-binding protein 28 & RBM28 & $2.63 \mathrm{E}+01$ & $5.02 \mathrm{E}-03$ \\
\hline RNA-binding motif protein, $\mathrm{X}$ chromosome & RBMX & $3.01 E+01$ & $8.90 \mathrm{E}-03$ \\
\hline RNA 3-terminal phosphate cyclase-like protein & RCL1 & $2.65 E+01$ & $1.64 \mathrm{E}-03$ \\
\hline Reticulocalbin-2 & RCN2 & $2.73 E+01$ & 2.67E-03 \\
\hline Replication factor $C$ subunit 3 & RFC3 & $2.62 \mathrm{E}+01$ & $2.34 \mathrm{E}-02$ \\
\hline Telomere-associated protein RIF1 & RIF1 & $3.04 E+01$ & $9.16 \mathrm{E}-03$ \\
\hline Serine/threonine-protein kinase RIO1 & RIOK1 & $3.02 \mathrm{E}+01$ & $3.05 \mathrm{E}-03$ \\
\hline RING finger protein 219 & RNF219 & $2.94 \mathrm{E}+01$ & $2.50 \mathrm{E}-03$ \\
\hline RNA-binding protein 39 & RNPC2 & $2.86 \mathrm{E}+01$ & $8.92 \mathrm{E}-03$ \\
\hline $60 S$ ribosomal protein L10 & RPL10 & $3.26 \mathrm{E}+01$ & $7.84 \mathrm{E}-03$ \\
\hline $60 S$ ribosomal protein L10a & RPL10A & $3.22 \mathrm{E}+01$ & $2.24 \mathrm{E}-02$ \\
\hline 605 ribosomal protein L11 & RPL11 & $3.19 \mathrm{E}+01$ & $1.04 \mathrm{E}-03$ \\
\hline 605 ribosomal protein L12 & RPL12 & $3.18 \mathrm{E}+01$ & $6.43 \mathrm{E}-03$ \\
\hline 605 ribosomal protein L13 & RPL13 & $3.30 \mathrm{E}+01$ & $4.30 \mathrm{E}-04$ \\
\hline $60 S$ ribosomal protein L13a & RPL13A & $3.17 \mathrm{E}+01$ & $2.25 \mathrm{E}-03$ \\
\hline $60 S$ ribosomal protein L14 & RPL14 & $3.07 E+01$ & $7.88 \mathrm{E}-04$ \\
\hline $60 S$ ribosomal protein L15 & RPL15 & $5.67 \mathrm{E}+00$ & $8.90 \mathrm{E}-03$ \\
\hline $60 S$ ribosomal protein L17 & RPL17 & $3.16 \mathrm{E}+01$ & $4.69 \mathrm{E}-04$ \\
\hline 605 ribosomal protein L18 & RPL18 & $3.28 \mathrm{E}+01$ & $1.68 \mathrm{E}-03$ \\
\hline $60 S$ ribosomal protein L18a & RPL18A & $3.24 \mathrm{E}+01$ & $2.10 \mathrm{E}-03$ \\
\hline Ribosomal protein L19 & RPL19 & $3.26 \mathrm{E}+01$ & $4.36 \mathrm{E}-03$ \\
\hline $60 S$ ribosomal protein L21 & RPL21 & $3.11 E+01$ & $1.99 \mathrm{E}-03$ \\
\hline $60 S$ ribosomal protein L22 & RPL22 & $3.05 E+01$ & $1.47 \mathrm{E}-03$ \\
\hline 605 ribosomal protein L22-like 1 & RPL22L1 & $2.70 \mathrm{E}+01$ & $6.60 \mathrm{E}-03$ \\
\hline $60 S$ ribosomal protein L23 & RPL23 & $3.09 E+01$ & 4.70E-03 \\
\hline $60 S$ ribosomal protein L23a & RPL23A & $3.24 \mathrm{E}+01$ & $1.26 \mathrm{E}-03$ \\
\hline 605 ribosomal protein L24 & RPL24 & $3.03 E+01$ & $1.24 \mathrm{E}-03$ \\
\hline $60 S$ ribosomal protein L26 & RPL26 & $3.24 \mathrm{E}+01$ & $1.20 \mathrm{E}-03$ \\
\hline $60 S$ ribosomal protein L27 & RPL27 & $3.18 \mathrm{E}+01$ & $3.06 \mathrm{E}-03$ \\
\hline
\end{tabular}


Table 1 continued

\begin{tabular}{|c|c|c|c|}
\hline Protein name & Gene ID & Log2 ratio & $P$-value \\
\hline $60 S$ ribosomal protein L27a & RPL27A & $3.06 \mathrm{E}+01$ & 5.33E-04 \\
\hline $60 S$ ribosomal protein L28 & RPL28 & $3.22 \mathrm{E}+01$ & $6.23 \mathrm{E}-04$ \\
\hline 605 ribosomal protein L29 & RPL29 & $3.19 \mathrm{E}+01$ & $3.76 \mathrm{E}-04$ \\
\hline 605 ribosomal protein $\mathrm{L} 3$ & RPL3 & $7.15 \mathrm{E}+00$ & $6.72 \mathrm{E}-03$ \\
\hline $60 S$ ribosomal protein $L 30$ & RPL30 & $3.04 E+01$ & $2.06 \mathrm{E}-03$ \\
\hline 605 ribosomal protein L31 & RPL31 & $3.15 E+01$ & $3.12 \mathrm{E}-04$ \\
\hline 605 ribosomal protein L32 & RPL32 & $3.18 \mathrm{E}+01$ & $3.51 \mathrm{E}-04$ \\
\hline $60 S$ ribosomal protein L34 & RPL34 & $2.90 E+01$ & 4.73E-03 \\
\hline $60 S$ ribosomal protein L35 & RPL35 & $3.13 \mathrm{E}+01$ & 1.43E-02 \\
\hline $60 S$ ribosomal protein $\mathrm{L} 35 \mathrm{a}$ & RPL35A & $3.14 \mathrm{E}+01$ & $2.01 \mathrm{E}-02$ \\
\hline $60 S$ ribosomal protein L36 & RPL36 & $3.02 E+01$ & $1.49 \mathrm{E}-02$ \\
\hline $60 S$ ribosomal protein $\mathrm{L} 36 \mathrm{a}$ & RPL36A & 2.97E+01 & $5.51 \mathrm{E}-04$ \\
\hline $60 S$ ribosomal protein L37a & RPL37A & $3.07 E+01$ & $1.05 \mathrm{E}-04$ \\
\hline $60 S$ ribosomal protein L38 & RPL38 & $2.90 \mathrm{E}+01$ & $3.49 \mathrm{E}-02$ \\
\hline 605 ribosomal protein $L 4$ & RPL4 & $3.36 \mathrm{E}+01$ & $1.82 \mathrm{E}-03$ \\
\hline 605 ribosomal protein $L 5$ & RPL5 & $3.26 \mathrm{E}+01$ & $6.62 \mathrm{E}-03$ \\
\hline 605 ribosomal protein L6 & RPL6 & $6.39 E+00$ & $9.35 \mathrm{E}-03$ \\
\hline 605 ribosomal protein $L 7$ & RPL7 & $3.33 \mathrm{E}+01$ & $2.21 \mathrm{E}-03$ \\
\hline $60 S$ ribosomal protein $L 7 a$ & RPL7A & $8.22 \mathrm{E}+00$ & $1.74 \mathrm{E}-03$ \\
\hline 605 ribosomal protein L8 & RPL8 & $3.33 \mathrm{E}+01$ & $9.73 \mathrm{E}-04$ \\
\hline 605 ribosomal protein $L 9$ & RPL9 & $3.06 \mathrm{E}+01$ & $1.10 \mathrm{E}-04$ \\
\hline 605 acidic ribosomal protein P0 & RPLPO & $3.23 \mathrm{E}+01$ & $2.18 \mathrm{E}-03$ \\
\hline 605 acidic ribosomal protein P2 & RPLP2 & $2.87 \mathrm{E}+01$ & $4.32 \mathrm{E}-03$ \\
\hline $40 \mathrm{~S}$ ribosomal protein $\mathrm{S} 10$ & RPS10 & $3.21 E+01$ & $1.86 \mathrm{E}-03$ \\
\hline $40 S$ ribosomal protein $S 11$ & RPS11 & $3.24 \mathrm{E}+01$ & $1.88 \mathrm{E}-03$ \\
\hline $40 \mathrm{~S}$ ribosomal protein $\mathrm{S} 12$ & RPS12 & $3.14 \mathrm{E}+01$ & 4.05E-04 \\
\hline $40 \mathrm{~S}$ ribosomal protein $\mathrm{S} 13$ & RPS13 & $3.22 \mathrm{E}+01$ & $1.60 \mathrm{E}-03$ \\
\hline $40 S$ ribosomal protein $S 14$ & RPS14 & $3.15 E+01$ & $4.92 \mathrm{E}-04$ \\
\hline $40 \mathrm{~S}$ ribosomal protein S15 & RPS15 & $3.15 E+01$ & $3.33 \mathrm{E}-02$ \\
\hline $40 \mathrm{~S}$ ribosomal protein $\mathrm{S} 15 \mathrm{a}$ & RPS15A & $3.19 E+01$ & 1.70E-03 \\
\hline $40 S$ ribosomal protein $\$ 16$ & RPS16 & $3.24 \mathrm{E}+01$ & $1.08 \mathrm{E}-03$ \\
\hline $40 S$ ribosomal protein $\mathrm{S} 17$ & RPS17 & $3.19 \mathrm{E}+01$ & $1.78 \mathrm{E}-03$ \\
\hline $40 \mathrm{~S}$ ribosomal protein $\mathrm{S} 18$ & RPS18 & $8.03 E+00$ & $7.90 \mathrm{E}-09$ \\
\hline $40 S$ ribosomal protein $\$ 19$ & RPS19 & $3.22 \mathrm{E}+01$ & $1.65 \mathrm{E}-03$ \\
\hline $40 S$ ribosomal protein $\mathrm{S} 2$ & RPS2 & $3.28 \mathrm{E}+01$ & $1.71 \mathrm{E}-03$ \\
\hline 40 S ribosomal protein S20 & RPS20 & $3.21 E+01$ & 4.89E-04 \\
\hline 40 S ribosomal protein S21 & RPS21 & $2.88 \mathrm{E}+01$ & $2.47 \mathrm{E}-03$ \\
\hline $40 S$ ribosomal protein $\$ 23$ & RPS23 & $3.25 E+01$ & $1.31 \mathrm{E}-03$ \\
\hline 40 S ribosomal protein $\$ 24$ & RPS24 & $3.00 \mathrm{E}+01$ & $1.10 \mathrm{E}-04$ \\
\hline 40 S ribosomal protein S25 & RPS25 & $3.14 \mathrm{E}+01$ & $5.19 \mathrm{E}-03$ \\
\hline
\end{tabular}


Table 1 continued

\begin{tabular}{|c|c|c|c|}
\hline Protein name & Gene ID & Log2 ratio & $P$-value \\
\hline $40 S$ ribosomal protein $\$ 26$ & RPS26 & $3.08 \mathrm{E}+01$ & $2.54 \mathrm{E}-02$ \\
\hline 40 S ribosomal protein $\$ 27$ & RPS27 & $3.00 \mathrm{E}+01$ & 3.65E-03 \\
\hline $40 S$ ribosomal protein $\mathrm{S} 3$ & RPS3 & $3.28 \mathrm{E}+01$ & $3.26 \mathrm{E}-03$ \\
\hline $40 \mathrm{~S}$ ribosomal protein S3a & RPS3A & $3.30 \mathrm{E}+01$ & 4.75E-04 \\
\hline $40 \mathrm{~S}$ ribosomal protein $\mathrm{S} 4, \mathrm{X}$ isoform & RPS4X & $6.65 \mathrm{E}+00$ & $2.28 \mathrm{E}-03$ \\
\hline $40 S$ ribosomal protein $\mathrm{S} 6$ & RPS6 & $3.18 \mathrm{E}+01$ & $2.28 \mathrm{E}-03$ \\
\hline $40 S$ ribosomal protein $\mathrm{S7}$ & RPS7 & $3.28 \mathrm{E}+01$ & $1.99 \mathrm{E}-02$ \\
\hline $40 S$ ribosomal protein 58 & RPS8 & $3.24 \mathrm{E}+01$ & 3.63E-03 \\
\hline $40 S$ ribosomal protein 59 & RPS9 & $3.31 \mathrm{E}+01$ & $3.94 \mathrm{E}-03$ \\
\hline $40 S$ ribosomal protein SA & RPSA & $3.32 \mathrm{E}+01$ & $1.29 \mathrm{E}-03$ \\
\hline Ribosome-binding protein 1 & RRBP1 & $2.84 \mathrm{E}+01$ & $3.20 \mathrm{E}-02$ \\
\hline RRP12-like protein & RRP12 & $2.58 \mathrm{E}+01$ & 1.13E-02 \\
\hline Ribosomal L1 domain-containing protein 1 & RSL1D1 & $2.69 \mathrm{E}+01$ & $1.56 \mathrm{E}-02$ \\
\hline U4/U6.U5 tri-snRNP-associated protein 1 & SART1 & $2.91 \mathrm{E}+01$ & $1.18 \mathrm{E}-04$ \\
\hline Splicing factor, arginine/serine-rich 15 & SCAF4 & $2.74 \mathrm{E}+01$ & $1.68 \mathrm{E}-02$ \\
\hline Protein SDA1 homolog & SDAD1 & $2.64 \mathrm{E}+01$ & 1.69E-02 \\
\hline Plasminogen activator inhibitor 1 RNA-binding protein & SERBP1 & $3.28 \mathrm{E}+01$ & 2.19E-02 \\
\hline Splicing factor 3B subunit 1 & SF3B1 & $2.81 E+01$ & 8.87E-03 \\
\hline Splicing factor 3B subunit 3 & SF3B3 & $2.72 \mathrm{E}+01$ & $1.14 \mathrm{E}-02$ \\
\hline Superkiller viralicidic activity 2-like 2 & SKIV2L2 & $2.75 \mathrm{E}+01$ & 8.05E-03 \\
\hline U5 small nuclear ribonucleoprotein $200 \mathrm{kDa}$ helicase & SNRNP200 & $3.06 \mathrm{E}+01$ & $5.98 \mathrm{E}-03$ \\
\hline U5 small nuclear ribonucleoprotein $40 \mathrm{kDa}$ protein & SNRNP40 & $2.72 \mathrm{E}+01$ & $1.41 \mathrm{E}-02$ \\
\hline Small nuclear ribonucleoprotein Sm D1 & SNRPD1 & $3.02 \mathrm{E}+01$ & $1.48 \mathrm{E}-03$ \\
\hline Small nuclear ribonucleoprotein Sm D2 & SNRPD2 & $2.92 \mathrm{E}+01$ & $2.94 \mathrm{E}-04$ \\
\hline Small nuclear ribonucleoprotein Sm D3 & SNRPD3 & $2.95 E+01$ & $1.93 \mathrm{E}-02$ \\
\hline Small nuclear ribonucleoprotein-associated proteins B and B & SNRPN & $3.06 \mathrm{E}+01$ & 4.62E-04 \\
\hline Spectrin alpha chain, non-erythrocytic 1 & SPTAN1 & $3.41 E+01$ & 9.63E-04 \\
\hline Spectrin beta chain, non-erythrocytic 1 & SPTBN1 & $3.41 \mathrm{E}+01$ & $9.41 \mathrm{E}-05$ \\
\hline SRSF protein kinase 1 & SRPK1 & $2.94 \mathrm{E}+01$ & $5.81 \mathrm{E}-03$ \\
\hline SRSF protein kinase 2 & SRPK2 & $2.60 \mathrm{E}+01$ & $2.88 \mathrm{E}-02$ \\
\hline Serine/arginine repetitive matrix protein 1 & SRRM1 & $2.85 E+01$ & 1.46E-02 \\
\hline Serrate RNA effector molecule homolog & SRRT & $2.57 \mathrm{E}+01$ & $2.04 \mathrm{E}-03$ \\
\hline Serine/arginine-rich splicing factor 1 & SRSF1 & $2.74 \mathrm{E}+01$ & 1.86E-04 \\
\hline Serine/arginine-rich splicing factor 2 & SRSF2 & $2.69 E+01$ & 4.59E-02 \\
\hline Serine/arginine-rich splicing factor 3 & SRSF3 & $2.87 E+01$ & $1.42 \mathrm{E}-03$ \\
\hline Double-stranded RNA-binding protein Staufen homolog 1 & STAU1 & $2.88 \mathrm{E}+01$ & $1.18 \mathrm{E}-02$ \\
\hline Serine/threonine-protein kinase 38 & STK38 & $2.78 \mathrm{E}+01$ & $2.59 \mathrm{E}-02$ \\
\hline SUN domain-containing protein 2 & SUN2 & $2.97 \mathrm{E}+01$ & $6.35 \mathrm{E}-04$ \\
\hline Heterogeneous nuclear ribonucleoprotein Q & SYNCRIP & $2.82 \mathrm{E}+01$ & $1.08 \mathrm{E}-02$ \\
\hline Very-long-chain enoyl-CoA reductase & TECR & $2.70 \mathrm{E}+01$ & 4.59E-03 \\
\hline
\end{tabular}


Table 1 continued

\begin{tabular}{|c|c|c|c|}
\hline Protein name & Gene ID & Log2 ratio & $P$-value \\
\hline Testis-expressed sequence 10 protein & TEX10 & $2.64 \mathrm{E}+01$ & $1.64 \mathrm{E}-03$ \\
\hline THO complex subunit 2 & $\mathrm{THOC2}$ & $2.53 \mathrm{E}+01$ & 1.37E-02 \\
\hline Tight junction protein ZO-2 & TJP2 & $2.65 E+01$ & $6.69 \mathrm{E}-03$ \\
\hline Transmembrane protein 33 & TMEM33 & $2.74 \mathrm{E}+01$ & $1.11 \mathrm{E}-02$ \\
\hline Tropomodulin-3 & TMOD3 & $2.63 \mathrm{E}+01$ & $4.62 \mathrm{E}-03$ \\
\hline TRMT1-like protein & TRMT1L & $2.82 \mathrm{E}+01$ & $9.34 \mathrm{E}-03$ \\
\hline Tubulin beta-3 chain & TUBB3 & $2.57 E+01$ & $5.04 \mathrm{E}-04$ \\
\hline Tubulin beta-4A chain & TUBB4A & $2.61 E+01$ & $2.90 \mathrm{E}-02$ \\
\hline Splicing factor U2AF $35 \mathrm{kDa}$ subunit & U2AF1 & $2.90 \mathrm{E}+01$ & $7.02 \mathrm{E}-03$ \\
\hline Splicing factor U2AF $65 \mathrm{kDa}$ subunit & U2AF2 & $2.98 \mathrm{E}+01$ & $4.30 \mathrm{E}-03$ \\
\hline U2 snRNP-associated SURP motif-containing protein & U2SURP & $2.78 \mathrm{E}+01$ & $1.78 \mathrm{E}-05$ \\
\hline E3 ubiquitin-protein ligase UBR5 & UBR5 & $2.78 \mathrm{E}+01$ & $2.75 \mathrm{E}-02$ \\
\hline U4/U6.U5 tri-snRNP-associated protein 2 & USP39 & $2.88 \mathrm{E}+01$ & $2.14 \mathrm{E}-02$ \\
\hline Transitional endoplasmic reticulum ATPase & VCP & $2.80 E+01$ & $7.61 \mathrm{E}-05$ \\
\hline Vimentin & VIM & $1.35 E+00$ & $2.08 \mathrm{E}-02$ \\
\hline Methylosome protein 50 & WDR77 & $3.30 E+01$ & $2.27 \mathrm{E}-02$ \\
\hline Exportin- $T$ & XPOT & $2.64 E+01$ & $7.27 \mathrm{E}-03$ \\
\hline Nuclease-sensitive element-binding protein 1 & YBX1 & $3.07 \mathrm{E}+01$ & $3.00 \mathrm{E}-03$ \\
\hline YTH domain-containing protein 1 & YTHDC1 & $2.78 \mathrm{E}+01$ & $8.82 \mathrm{E}-03$ \\
\hline YTH domain-containing family protein 2 & YTHDF2 & $1.60 E+00$ & $3.42 \mathrm{E}-02$ \\
\hline Zinc finger $\mathrm{CCCH}$ domain-containing protein 18 & ZC3H18 & $2.79 E+01$ & $1.14 \mathrm{E}-02$ \\
\hline Zinc finger CCCH-type antiviral protein 1 & ZC3HAV1 & $2.79 E+01$ & $1.27 \mathrm{E}-02$ \\
\hline Zinc finger protein 622 & ZNF622 & $2.75 \mathrm{E}+01$ & $1.14 \mathrm{E}-02$ \\
\hline
\end{tabular}

Log2 ratio and $p$-values were calculated using measured protein intensities, i.e. eXtracted lon Current (XIC) of all isotopic clusters associated with the identified amino acid sequence. Log 2 ratio was calculated from the intensity sum of samples/ controls. $p$-values are the result of a two-sided t-test, samples vs. control. In cases where intensities had been measured in 2 (out of 3 ) replicates, the third intensity value was added through imputation. If no intensity could be measured in all 3 replicates, the intensities were set from 0 to 1 in order to still be able to calculate a ratio (same applies to cases where only 1 intensity could be measured)
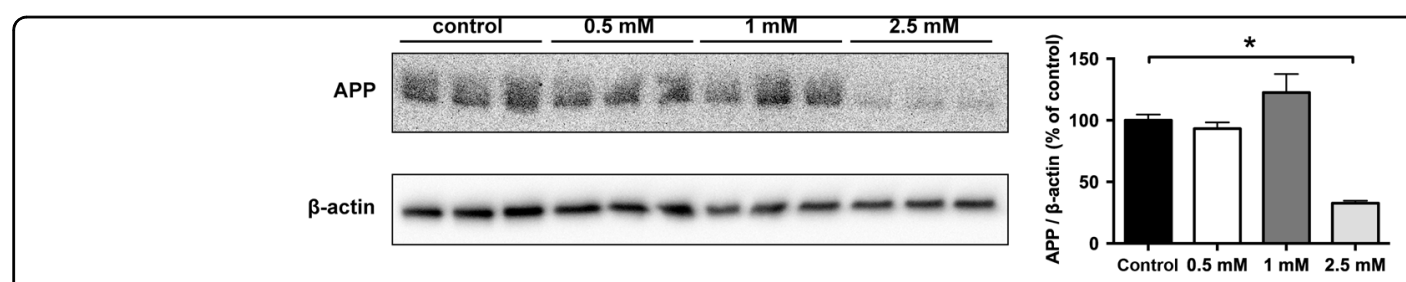

Fig. 3 Disruption of the MID1-complex by metformin reduces APP protein level. Primary neurons were treated with different doses of metformin. Protein extracts were analyzed on western blots detecting APP and $\beta$-actin as loading control. Graph shows quantification of western blots, mean values \pm SEM. $n=3{ }^{*} p<0.01$. APP amyloid precursor protein

In summary, all these data suggest that metformin inhibits the MID1-dependent translation of APP and thereby reduces $A \beta$ plaque burden and improves cognitive impairments in an AD mouse model.

\section{Discussion}

In this study, we show a novel regulatory mechanism controlling the protein synthesis of APP: this mechanism involves the MID1 protein, which induces the translation 

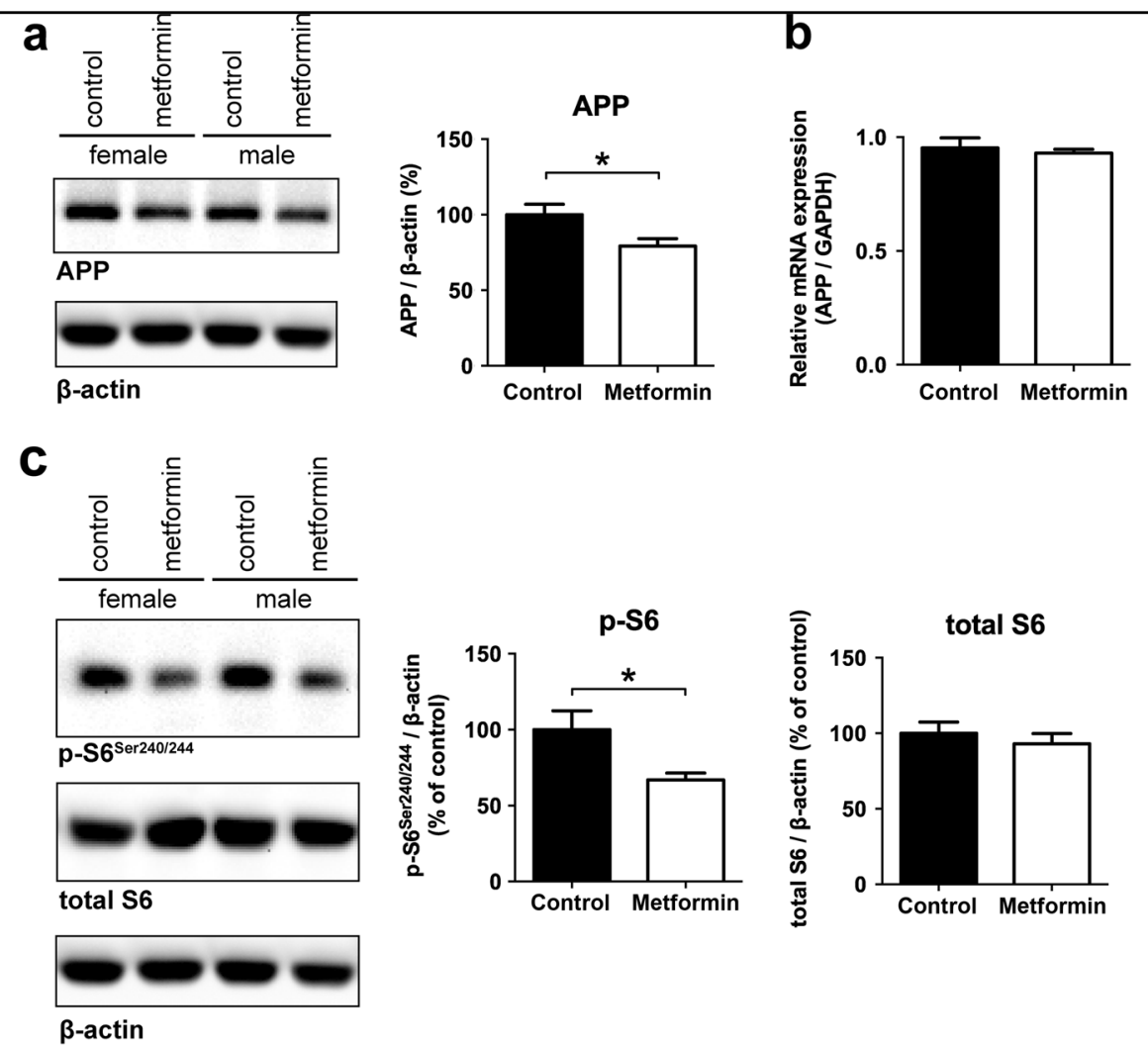

Fig. 4 Metformin reduces APP protein level in mice. Male and female APP/PS1 mice (age 12-13 months) were treated for 8 months with 5 $\mathbf{g} / \mathbf{l}$ metformin in the drinking water. a Protein extracts from brain tissue of these animals were analyzed on western blots detecting APP and $\beta$-actin as loading control. A representative blot of $n=3$ males and $n=4$ females is shown. Graphs show quantification of western blots, mean values \pm SEM. ${ }^{*}=p<0.05$. $\mathbf{b}$ Relative APP mRNA expression was measured in brain tissues described in a by means of real-time PCR. Columns represent mean values \pm SEM. $n=5$. $\mathbf{c}$ Protein extracts from brain tissue of these animals was analyzed on western blots, detecting phospho-S6 ( $p$-S6), total S6 and $\beta$-actin as loading control. A representative blot of $n=6$ is shown. Graphs show quantification of western blots, mean values \pm SEM. ${ }^{*}=p<0.05$

of APP by regulating mTOR-eIF signaling. Disassembly of the MID1 protein complex by metformin reduces the protein production of APP. Furthermore, we show that chronic treatment of $\mathrm{AD}$ mice with metformin decreases the protein level of APP and its cleavage products, including $A \beta$. This together with our previous observation that disassembly of the MID1 protein complex by metformin also decreases tau-phosphorylation ${ }^{7}$, makes MID1 a particularly interesting drug target for treating $\mathrm{AD}$.

Among other effects, metformin induces PP2A activity by interfering with the assembly of the MID1-PP2Acomplex ${ }^{7}$. Although MID1 has an inhibitory effect on $\mathrm{PP}^{8} \mathrm{~A}^{8}$, it positively regulates $\mathrm{mTOR}^{9}$. Therefore, metformin activates PP2A, while at the same time it suppresses mTOR. Decreased mTOR signalling results in activation of autophagy and decreased translation of mRNAs regulated by its downstream effectors S6K and $4 \mathrm{E}-\mathrm{BP} 1^{21}$. The MID1 protein complex via PP2A and mTOR stimulates translation of mRNAs that are associated with this protein complex, some of which play a role in neurodegeneration ${ }^{11-13,16}$.
Here we identified APP mRNA as a novel binding partner of MID1, suggesting that the MID1 complex also induces its translation. Since the biguanide metformin interferes with the assembly of the MID1 protein complex, it thereby reduces translation of the APP mRNA, leading to decreased processing by the amyloidogenic pathway. This mode of action of metformin has also been shown for other mRNAs that are associated with the MID1-complex, including the androgen receptor (AR) and BACE1 mRNA ${ }^{14,15}$. Furthermore, we report a so far unknown additional connection between MID1 and the mTOR-dependent translation initiation pathway: MID1 binds to RPLP0, a protein of the large ribosomal subunit. Metformin treatment interferes with the MID1-complex assembly and thus inhibits MID1-dependent translation $^{7,14,15}$. Overall, metformin seems to decrease translation of several MID1-PP2A-mTOR dependent mRNAs. However, since chronic administration of metformin is well tolerated in type 2 diabetes patients, this does not seem to be particularly deleterious. Additionally, both induction of autophagy and reduced protein translation 

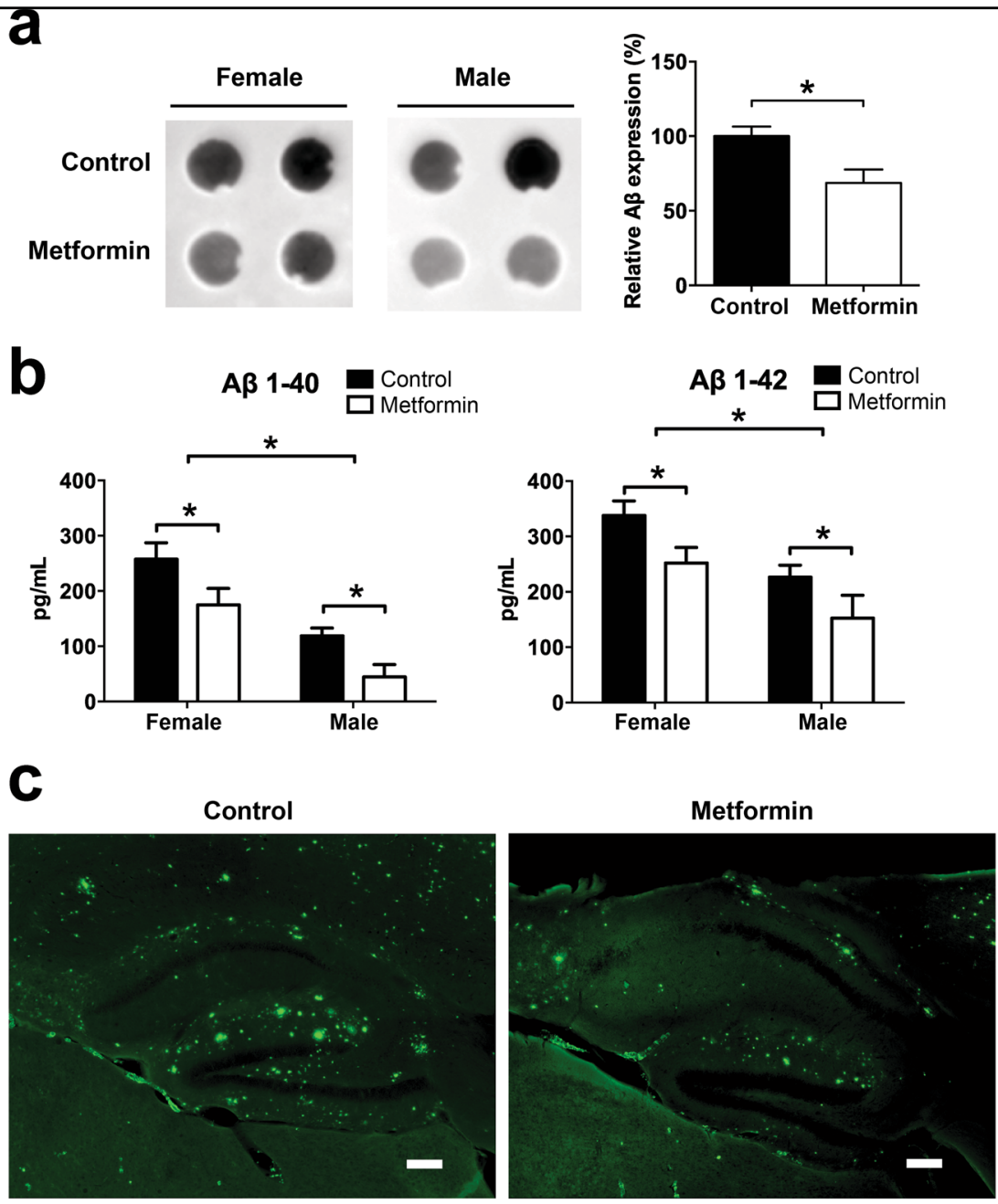

d

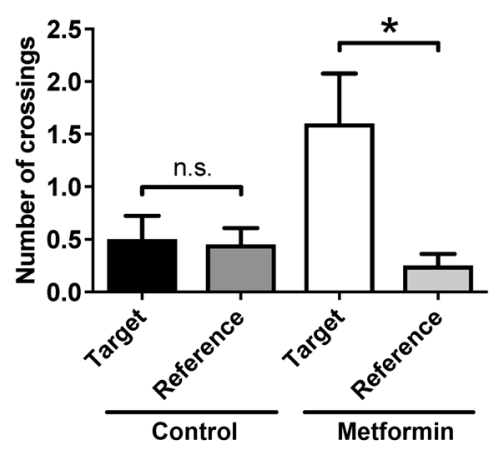

Fig. 5 Metformin reduces A $\beta$ plaque burden in mice. Male and female APP/PS1 mice (age 12-13 months) were treated for 8 months with $\mathbf{5 g} / \mathbf{l}$ metformin in the drinking water. a Protein extracts from brain tissue of these animals was analyzed on dot blots detecting $A \beta$. Representative blots of $n=4$ females and $n=3$ males are shown. Graphs show quantification of dot blots, mean values \pm SEM, the mean value of control animals was set to $100 \%$. ${ }^{*} p<0.05$. b ELISA measurements of A $\beta$ in brain tissues described in $\mathbf{a}$. Columns represent mean values $(\mathrm{pg} / \mathrm{ml}) \pm \mathrm{SEM}$. $n=4 \mathrm{females}$, $n=3$ males. ${ }^{*} p<0.05$. c Sagittal brain sections of mice were stained with Thioflavin-S for A $\beta$ aggregates. Scale bar $=200 \mu \mathrm{m} \mathbf{d}$ Spatial learning and memory in the Morris water maze. Mice were trained on a hidden version of the Morris water maze. After completion of training, we performed a probe trial to test how accurately the animals had learned the location of the escape platform (target). The graph shows the number of crossings of the target location vs. averaged crossings of corresponding positions in the adjacent, non-target quadrants (reference). Shown are means \pm SEM. $n=10$ mice per group. ${ }^{*} p<0.05$ 


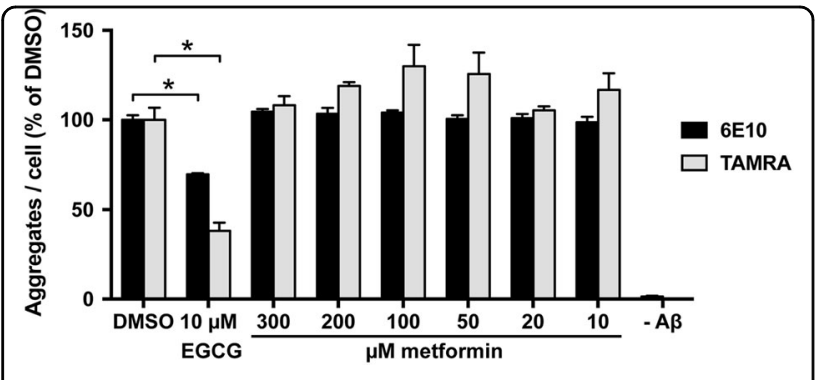

Fig. 6 Metformin treatment does not induce degradation of $A \beta$. Determination of cellular A 42 aggregate loads in SH-EP cells containing TAMRA-A $\beta 42$ aggregates. Cells were treated with different amounts of metformin and $A \beta 42$ aggregate load was quantified by automated fluorescence microscopy. Aggregates per cell were either quantified by the TAMRA-labeling or alternatively by

immunofluorescence using the 6E10-A -antibody. ECGC, a substance that was previously reported to remodel $A \beta$ fibrils ${ }^{32,33}$, was used as positive control. Graph show mean values \pm SEM. $n=3 .{ }^{*} p<0.001$

are especially vital for the adult nervous system, since these processes control homeostasis of $\mathrm{A} \beta$ and phospho$\operatorname{tau}^{19,20}$. Therefore, we believe that reduced protein translation of several mRNAs regulated by MID1/PP2A/ mTOR would be beneficial.

The use of metformin as a putative drug for treating AD has been discussed controversially ${ }^{15,21-27}$. While in some studies metformin treatment increased $\mathrm{APP}^{27}$ or $\mathrm{A} \beta$ levels ${ }^{24}$, other studies showed that metformin attenuated AD-like neuropathology for example by decreasing the level of the APP processing enzyme BACE $1^{15}$, or by decreasing tau hyperphosphorylation ${ }^{7,25}$. This discrepancy can be explained by differences in the experimental set-up in the different studies. First, the effect of metformin seems to be dose- and time-dependent. For example, in cell culture models high doses of metformin $(5-50 \mathrm{mM})$ or long incubation times result in an increased expression of APP and BACE1 ${ }^{24,27}$, while lower doses (1-2.5 mM) decrease BACE1 protein levels as well as APP cleavage products and tau phosphorylation ${ }^{7,15,23}$. In wildtype mice treatment with $2 \mathrm{~g} / \mathrm{l}$ metformin in the drinking water results in increased expression of BACE1 and APP as well as APP cleavage products ${ }^{24,27}$, while treatment with 5 $\mathrm{g} / \mathrm{l}$ reduces BACE1 protein expression ${ }^{15}$ as well as tauphosphorylation ${ }^{7}$. Also the period of treatment seems to be important. Different to studies in which increased APP and BACE1 levels were detected ${ }^{24,27}$, our study lasted over a treatment period of 8 months. Therefore, differences between acute and chronic pharmacological treatments could account for the observed effects. Of note, in our experiments we detected a significant difference in $\mathrm{A} \beta$ levels between female and male mice, with female mice having an increased $A \beta$ burden compared to male mice. This observation is in line with previous findings, showing that female mice exhibit much higher $\gamma$-secretase activity in aged brain compared to male mice and therefore, $A \beta$ plaque pathology in female mouse models of $A D$ is increased compared to males ${ }^{28}$. Interestingly, another study in which metformin had been used in a chronic treatment demonstrated that learning and memory were improved by metformin treatment in female mice, while it had an opposite effect in male mice ${ }^{26}$. This shows that also the sex of the experimental animals used could account for different findings. Another important point is the age of the experimental animals in which the treatment was initiated. To our knowledge our study is the first study in which metformin treatment was initiated in aged mice displaying an already progressed state of the disease.

Taken together, our study shows that long-term treatment with metformin inhibits the MID1-dependent translation of APP and thus reduces A $\beta$ plaque burden without any side effects for the animals. The administration of metformin for a prolonged period (8 months) started late in life and in an already progressed state of the disease. Therefore, our data represent the effects of metformin on biochemical and cognitive changes of the CNS in a progressed disease stage of $\mathrm{AD}$. In addition, we could show in our previous work, that disassembly of the MID1 protein complex by metformin also decreases tauphosphorylation ${ }^{7}$, making the MID1 complex a particularly interesting target for treating all $\mathrm{AD}$ neuropathologies.

\section{Materials and methods}

\section{In vitro translation}

To create an hAPP-Luciferase fusion construct, the human APP wild type splice variant 695 cDNA sequence was amplified by PCR from the pcDNA-hAPP695wt plasmid using primers APP-pGL3m-fwd and APP-pGL3m-rev (Table 2), thereby creating HindIII and NcoI restriction sites, which were used to insert the amplified sequence into the pGL3m plasmid ${ }^{11} 5^{\prime}$ of the firefly luciferase sequence. To enable in vitro transcription, a T7 site was inserted by PCR using primers T7-hAPP-ivts-fwd and pGL3-2258ivts-rev (Table 2). The resulting amplificate was phenolchloroform purified and subjected to in vitro transcription using the RiboMAX ${ }^{\mathrm{TM}}$ Large scale RNA production system-T7 (Promega, Mannheim, Germany) according to the manufacturer's instructions. In vitro transcribed RNA was phenol-chloroform purified and translated in vitro using the Flexi Rabbit Reticulocyte Lysate System (Promega) in presence or absence of inhibitors. Luciferase activity was quantified using the Firefly Luciferase Assay System (Promega) on a FLUOstar Omega 96-well plate reader (BMG Labtech, Ortenberg, Germany).

\section{Immunoprecipitation}

Cells have been authenticated by PCR-single-locustechnology (service by Eurofins (Ebersberg, Germany)) in December 2016. HEK293T cells were transfected with 
Table 2 Primer sequences

\begin{tabular}{ll}
\hline mAPP-RT-fwd & CAC ATC GTG ATT CCT TAC CG \\
mAPP-RT-rev & GTC TCA CAA ACA TCC ATC CG \\
mGAPDH-RT-fwd & GCA CAG TCA AGG CCG AGA AT \\
mGAPDH-RT-rev & GCC TTC TCC ATG GTG GTG AA \\
APP-pGL3m-fwd & TGC AAA AAG CTT GGC ATT CCG GTA CTG TTG GTA AAG CCA \\
APP-pGL3m-rev & CGT CTT CCA TGG CGC CTG GAC CGT TCT GCA TCT GCT CAA AGA ACT TGT AGG T \\
T7-hAPP-ivts-fwd & CGA AAT TAA TAC GAC TCA CTA TAG GGG TAA AGC CAC CAT GCT GCC CGG TाT GGC ACT GC \\
pGL3-2258-ivts-rev & CCG CGC CCA CCG GAA GGA GCT GAC TGG \\
\hline
\end{tabular}

pCMV-MID1-Tag2A using PolyFect (Qiagen, Hilden, Germany) according to the manufacturer's instructions. Untransfected cells were used as control. Cell pellets were lysed in TKM buffer (20 mM Tris pH 7.4, $100 \mathrm{mM} \mathrm{KCl,} 5$ $\mathrm{mM} \mathrm{MgCl}_{2}, 0.5 \% \mathrm{NP} 40,1 \mathrm{mM}$ DTT, protease inhibitors) using a Precellys cell homogenizer. For pre-clearing, 200 $\mu \mathrm{l}$ of IgG-agarose beads were added to the lysates and incubated rotating for $30 \mathrm{~min}$ at $4{ }^{\circ} \mathrm{C}$. The beads were pelleted for $5 \mathrm{~min}$ at $21,000 \mathrm{x}$ g. Precleared lysates were then added to $200 \mu \mathrm{l}$ anti-FLAG M1 Agarose Affinity Gel (Sigma-Aldrich/Merck, Darmstadt, Germany). After overnight rotation at $4{ }^{\circ} \mathrm{C}$, the beads were washed 6 times and resuspended in $50 \mu \mathrm{l} 1 \mathrm{x}$ SDS Buffer and boiled for 10 $\min$ at $95^{\circ} \mathrm{C}$. The proteins were then either identfied by mass spectrometry analysis or analyzed on a western blot. For ribosome disassembly, immunoprecipitation was performed in TKM buffer containing $40 \mathrm{mM}$ EDTA. For RNase digest, the beads were washed three times after overnight incubation, anti-FLAG beads were split into two aliquots and resuspended in NEBuffer 3 (B7003S, New England Biolabs, Frankfurt, Germany). RNase If (M0243, New England Biolabs) was added to a final concentration of $500 \mathrm{U} / \mathrm{ml}$ to one immunoprecipitate and incubated for $45 \mathrm{~min}$ at $37^{\circ} \mathrm{C}$. Subsequently, beads were washed three times and treated as described above.

\section{Mass spectrometry}

The eluted proteins were concentrated into one band on an SDS-PAGE gel. The band was excised and the proteins contained were processed using an automated sample preparation setup ${ }^{29}$. The generated peptides were purified on StageTips ${ }^{30}$. Samples were measured on a QExactive mass spectrometer (Thermo-Fisher, Waltham, MA, USA) coupled to a Proxeon nano-LC system (Thermo-Fisher) in data-dependent acquisition mode, selecting the top 10 peaks for HCD fragmentation. A $1 \mathrm{~h}$ gradient (solvent A: $5 \%$ acetonitrile, $0.1 \%$ formic acid; solvent B: $80 \%$ acetonitrile, $0.1 \%$ formic acid) was applied for the samples using an in-house prepared nano-LC column $(0.075 \mathrm{mM} \times 150 \mathrm{mM}, 3 \mu \mathrm{m}$ Reprosil C18, Dr.
Maisch GmbH, Ammerbuch-Entringen, Germany). A volume of $2 \mu \mathrm{l}$ sample was injected and peptides were eluted with $3 \mathrm{~h}$ gradients of $5-75 \%$ solvent $\mathrm{B}$ at flow rates of $0.25 \mu \mathrm{l} / \mathrm{min}$. MS acquisition was performed at a resolution of 70,000 in the scan range from 300 to $1700 \mathrm{~m} / \mathrm{z}$. The normalized collision energy was set to $26 \mathrm{eV}$. The mass window for precursor ion selection was set to $2.0 \mathrm{~m} /$ $z$. The recorded spectra were analyzed using the MaxQuant software package (Version 1.3 .0 .5$)^{31}$ by matching the data to the Uniprot human database (downloaded on 06.05.2012) with a false discovery rate (FDR) of $1 \%$.

\section{Peptide treatments}

Murine primary cortical neurons were treated with 2.5 $\mu \mathrm{M}$ of a peptide that mimics the MID1- $\alpha 4$ binding site and thus outcompetes MID1 from binding to $\alpha 4-P P 2 A c$. As control a mutant peptide was used. Peptides (GSK'364A and GSK'365A) containing a 29-residue sequence from $\alpha 4$ (AQAKVFGAGYPSLPTMTVSDWYEQHRKYG and AQAKVFGAGYPSLPTMTVSDWAEQHRKYG, respectively) with an N-terminal sequence derived from HIVTAT protein (RKKRRQRRR) were supplied by Cambridge Research Biochemicals (Billingham, UK). They were synthesized using standard automated solid-phase peptide synthesis via the $\mathrm{Fmoc} / \mathrm{tBu}$ strategy. Cleavage from the resin was performed using 95\% trifluoroacetic acid. Crudes were purified by preparative high-performance liquid chromatography (HPLC), freeze dried and characterized by high-performance liquid chromatography (HPLC) and matrix-assisted laser desorption ionization time-of-flight (MALDI-TOF) mass spectrometry.

\section{In vivo treatments mice}

Male and female APP/PS1 (B6C3-Tg(APPswe,PSEN1dE9) 85Dbo/Mmjax) mice (age 12-13 months) were treated for 8 months with $5 \mathrm{~g} / \mathrm{l}$ metformin in the drinking water with daily change of water and addition of fresh metformin. Water intake and body weight of the animals were monitored. After 8 months of treatment, animals were sacrificed and brains were snap-frozen in liquid nitrogen and broken up using a 
mortar. All procedures were in compliance with German Animal Protection Law and were approved by the competent authorities (Landesamt für Naturschutz und Verbraucherschutz Nordrhein-Westphalen; AZ 87-51.04.2011. A049/01).

\section{Morris water maze}

We assessed spatial learning and memory in the Morris water maze in APP/PS1 mice treated with metformin or vehicle control. The water pool (Med Associates) had a diameter of $1.2 \mathrm{~m}$ and was filled with opaque water (temperature: $24^{\circ} \mathrm{C}$ ). Mice received 6 daily training trials for 3 consecutive days on a hidden version of the Morris water maze (i.e., the maze contained an escape platform hidden underneath the water surface in a constant location of the pool). To evaluate the accuracy with which the animals had learned the position of the escape platform, we performed a probe trial (during which the platform was removed from the pool) once training was completed. Behavior of the animals was recorded using an automated tracking system (Ethovision XT, Noldus). We determined the number of crossings of the exact target location (i.e., where the platform was located during training) and compared it to the average crossings of analogous positions in the adjacent, non-target quadrants (reference).

\section{Thioflavin-S staining}

Sagittal brain sections were incubated in 1x TBS buffer containing $10 \%$ Triton X-100 and transferred onto glass slides. The slides were dried overnight at room temperature. Slides were washed 3 times for $3 \mathrm{~min}$ in distilled water, and incubated for $3 \mathrm{~min}$ in $0.1 \%$ Thioflavin-S staining solution (dissolved in $10 \%$ ethanol diluted in distilled water) in the dark. Sections were washed 3 times in distilled water and incubated for $20 \mathrm{~min}$ in $1 \%$ acetic acid in the dark. Slides were washed with tap water, cover-slipped with mounting medium (Thermo-Fisher), and stored in the dark at $4{ }^{\circ} \mathrm{C}$.

\section{Western blot}

Brain samples were homogenized either in RIPA buffer (20 mM Tris- $\mathrm{HCl}$ (pH 7.5), $150 \mathrm{mM} \mathrm{NaCl}, 1 \mathrm{mM}$ EDTA, 1 mM EGTA, 1\% NP-40, 1\% sodium deoxycholate, 2.5 $\mathrm{mM}$ sodium pyrophosphate, $1 \mathrm{mM} \beta$-glycerophosphate, 1 $\mathrm{mM} \mathrm{Na} \mathrm{VO}_{4}, 1 \mu \mathrm{g} / \mathrm{ml}$ leupeptin) or in SDS PAGE buffer B (40 mM Tris- $\mathrm{HCl}$ pH 6.8, 4\% Glycerol, 2\% SDS, 0.01\% bromophenolblue, $2 \mathrm{mM}$ 2-mercaptoethanol), sonicated and boiled for $5 \mathrm{~min}$ at $95^{\circ} \mathrm{C}$. Proteins were analyzed on 10 or $12 \%$ SDS gels and blotted onto PVDF membranes (Roche, Mannheim, Germany). Blots were blocked in milk and incubated with the antibodies listed below.

Bands were densitometrically quantified using AIDA software v4.27 (Raytest, Straubenhardt, Germany).

\section{Statistical analysis}

Statistical analyses were performed using two-way ANOVA, as well as Student's t-test or Mann-Whitney test (two-tailed) for two-group comparisons, as appropriate.

\section{Dot blot}

Brain samples were homogenized in RIPA buffer. $50 \mu \mathrm{g}$ total protein per well were loaded and proteins were transferred to a PVDF membrane using a HYBRI-DOT manifold. The aggregates on the membrane were detected by incubation with anti-beta-amyloid 6E10 antibodies (BioLegend, San Diego, CA, USA).

\section{ELISA}

ELISA assays to measure $A \beta$ were performed using the A $\beta 40$ / A $\beta 42$ ELISA Kits (Life Technologies) according to the manufacturer's protocol.

\section{Antibodies}

The following antibodies were purchased from Cell Signaling (Leiden, Netherlands): S6 (\#2317), pS6 (\#4858), actin (\#4967), eIF3A (\#3411), eIF4G (\#2498), RPL5 (\#51345) and GAPDH (\#2118). FLAG-HRP (A8592) antibody was purchased from Sigma; RPLP0 (ab192866), RPS3 (\#128995), and APP (ab2071) from Abcam (Cambridge, UK), and anti-beta-amyloid 6E10 from BioLegend (803001).

\section{Real-time PCR}

Total RNA was isolated using the RNeasy Plus Mini Kit (Qiagen). cDNA was synthesized using the TaqMan reverse transcription reagents kit (Applied Biosystems, Waltham, MA, USA) and real-time PCR was carried out using the SYBRGreen PCR master mix (Applied Biosystems). Primers used are listed in Table 2.

\section{RNA immunoprecipitation}

Murine primary cortical neurons were transfected with FLAG-tagged MID1 using Lipofectamine 2000 (Invitrogen Waltham, MA, USA). $48 \mathrm{~h}$ after transfection, cells were treated with or without $2.5 \mathrm{mM}$ metformin and incubated another $24 \mathrm{~h}$. After UV-crosslinking $(200 \mathrm{~mJ} /$ $\mathrm{cm}^{2}$ ) cells were lysed in TKM buffer (20 mM Tris pH 7.4, $100 \mathrm{mM} \mathrm{KCl}, 5 \mathrm{mM} \mathrm{MgCl}$, Complete protease inhibitor cocktail (Roche), RNAse inhibitor, 0.2\% NP40) and MID1 protein complexes were purified by immunoprecipitation using anti-FLAG M1 Agarose Affinity Gel (Sigma-Aldrich) or IgG-agarose (Sigma-Aldrich) as a negative control. Protein-bound mRNA was isolated after DNAse and proteinase $\mathrm{K}$ digestion by phenolchloroform purification and analyzed by RT-PCR. Primers used are listed in Table 2. 


\section{Automated fluorescence microscopy and determination of cellular $A \beta 42$ aggregate loads}

For fluorescent labeling of $A \beta$ aggregates, $20 \mu \mathrm{M} A \beta 42$ peptide stock solutions diluted in low salt buffer $(10 \mathrm{mM}$ $\mathrm{NaCl}, 1.9 \mathrm{KH}_{2} \mathrm{PO}_{4}, 8.1 \mathrm{mM} \mathrm{K}_{2} \mathrm{HPO}_{4}, \mathrm{pH} 7.4$ ) were mixed with $5 \% \mathrm{~A} \beta 42$ peptides which have been $\mathrm{N}$-terminally labeled with the fluorophore 5-Carboxytetramethylrhodamine (TAMRA) in solid-state peptide synthesis by AnsSpec, Fremont, USA. Then, mixed A $\beta$ peptide solutions were aggregated at $37^{\circ} \mathrm{C}$ for $18 \mathrm{~h}$ under $300 \mathrm{rpm}$ constant agitation followed by sonication with a Sonic Dismembrator Model 120 from Fisher Scientific GmbH (Schwerte, Germany) at low intensity for 6 rounds of $10 \mathrm{~s}$. SH-EP cells (DSMZ, Braunschweig, Germany) were cultured in DMEM (Gibco by Thermo-Fisher GmbH, Dreeich, Germany) containing 10\% fetal bovine serum (FBS), $5 \%$ Glucose, 100 units/ml penicillin and streptomycin, respectively. Incubation was carried out at $37^{\circ} \mathrm{C}$ with $5 \%(\mathrm{v} / \mathrm{v}) \mathrm{CO}_{2}$. For $\mathrm{A} \beta 42$ aggregate internalization, cells were treated with $600 \mathrm{nM}$ or $1 \mu \mathrm{M}$ TAMRA-A $\beta 42$ for 18 $h$. To ensure removal of free and surface-bound aggregates, $A \beta$ containing medium was aspirated, cells were washed with phosphate-buffered saline (PBS), trypsinized and collected in fresh medium. Then, cells were seeded into 96-well cell culture plates and treated with different amounts of metformin for $6 \mathrm{~h}$. Cells were fixed in $2 \%$ paraformaldehyde for $20 \mathrm{~min}$ at room temperature, followed by Nuclei staining with Hoechst (1:2500 Hoechst 33342, Sigma-Aldrich Chemie Gmbh Munich, Germany) and then washed twice with PBS, before fluorescent microscopy was performed in a Cellomics ArrayScan Hight-Content System (ThermoFisher) using an objective with 20 -fold magnification. After image acquisition, automated data analysis was performed using ArrayScan VTI (700 Series, Thermo-Fisher). For quantification, individual cells were detected via Hoechst fluorescent signals (XT53, filter and dichroic-emitter pair) and total TAMRA fluorescent areas per cell (XT32, filter and dichroic-emitter pair) were measured and calculated from technical triplicates. Alternatively, $\mathrm{A} \beta$ was stained by immunofluorescence using the 6E10 antibody (BioLegend).

\section{Acknowledgements}

This work was supported by the Else Kröner-Fresenius-Stiftung. We thank lain Uings at GlaxoSmithKline for supplying the peptides.

\begin{abstract}
Author details
${ }^{1}$ Deutsches Zentrum für Neurodegenerative Erkrankungen e.V., Bonn, Germany. ${ }^{2}$ Max Delbrueck Center for Molecular Medicine (MDC) Berlin-Buch, Berlin, Germany. ${ }^{3}$ Luxembourg Institute of Health, Strassen, Luxembourg
\end{abstract}

\section{Competing interests}

The authors declare that they have no competing interests.

Publisher's note: Springer Nature remains neutral with regard to jurisdictional claims in published maps and institutional affiliations.
Received: 15 September 2017 Accepted: 29 September 2017 Published online: 29 January 2018

\section{References}

1. Alzheimer, A., Stelzmann, R. A., Schnitzlein, H. N. \& Murtagh, F. R. An English translation of Alzheimer's 1907 paper, "Uber eine eigenartige Erkankung der Hirnrinde". Clin. Anat. 8, 429-431 (1995).

2. Walsh, J. S., Welch, H. G. \& Larson, E. B. Survival of outpatients with Alzheimertype dementia. Ann. Intern. Med. 113, 429-434 (1990).

3. Burns, A., Jacoby, R. \& Levy, R. Psychiatric phenomena in Alzheimer's disease. I: Disorders of thought content. Br. J. Psychiatr. 157, 72-76 (1990).

4. Alonso, A. D., Grundke-lqbal, I., Barra, H. S. \& lqbal, K. Abnormal phosphorylation of tau and the mechanism of Alzheimer neurofibrillary degeneration: sequestration of microtubule-associated proteins 1 and 2 and the disassembly of microtubules by the abnormal tau. Proc Natl Acad Sci U S A. 94, 298-303 (1997).

5. Gong, C. X., Liu, F., Grundke-lqbal, I. \& lqbal, K. Post-translational modifications of tau protein in Alzheimer's disease. J. Neural. Transm. 112, 813-838 (2005).

6. Tian, Q. \& Wang, J. Role of serine/threonine protein phosphatase in Alzheimer's disease. Neurosignals. 11, 262-269 (2002).

7. Kickstein, E. et al. Biguanide metformin acts on tau phosphorylation via mTOR/ protein phosphatase 2A (PP2A) signaling. Proc Natl Acad Sci U S A. 107, 21830-21835 (2010).

8. Trockenbacher, A. et al. MID1, mutated in Opitz syndrome, encodes an ubiquitin ligase that targets phosphatase 2A for degradation. Nat. Genet. 29, 287-294 (2001).

9. Liu, E., Knutzen, C. A., Krauss, S., Schweiger, S. \& Chiang, G. G. Control of mTORC1?signaling by the Opitz syndrome protein MID1. Proc Natl Acad Sci U S A. 108, 8680-8685 (2011).

10. Gingras, A.-C., Raught, B. \& Sonenberg, N. Regulation of translation initiation by FRAP/mTOR. Genes Dev. 15, 807-826 (2001).

11. Aranda-Orgilles, B. et al. Protein phosphatase 2A (PP2A)-specific ubiquitin ligase MID1 is a sequence-dependent regulator of translation efficiency controlling 3-phosphoinositide-dependent protein kinase-1 (PDPK-1). J. Biol. Chem. 286, 39945-39957 (2011).

12. Krauss, S. et al. Translation of HTT mRNA with expanded CAG repeats is regulated by the MID1-PP2A protein complex. Nat Commun. 4, 1511 (2013).

13. Aranda-Orgilles, B. et al. The Opitz syndrome gene product MID1 assembles a microtubule-associated ribonucleoprotein complex. Hum. Genet. 123, 163-176 (2008).

14. Demir, U., Koehler, A., Schneider, R., Schweiger, S. \& Klocker, H. Metformin anti-tumor effect via disruption of the MID1 translational regulator complex and AR downregulation in prostate cancer cells. BMC. Cancer. 14, 52 (2014).

15. Hettich, M. M. et al. The anti-diabetic drug metformin reduces BACE1 protein level by interfering with the MID1 complex. PLOS. ONE. 9, e102420 (2014).

16. Kohler, A. et al. A hormone-dependent feedback-loop controls androgen receptor levels by limiting MID1, a novel translation enhancer and promoter of oncogenic signaling. Mol. Cancer. 13, 146 (2014).

17. Nolan, R. D. \& Arnstein, H. R. The dissociation of rabbit reticulocyte ribosomes with EDTA and the location of messenger ribonucleic acid. Eur. J. Biochem. 9, 445-450 (1969).

18. Wullschleger, S., Loewith, R. \& Hall, M. N. TOR signaling in growth and metabolism. Cell. 124, 471-484 (2006).

19. O'Neill, C., Kiely, A. P., Coakley, M. F., Manning, S. \& Long-Smith, C. M. Insulin and IGF-1 signalling: longevity, protein homoeostasis and Alzheimer's disease. Biochem. Soc. Trans. 40, 721-727 (2012).

20. Caccamo, A., Majumder, S., Richardson, A., Strong, R. \& Oddo, S. Molecular interplay between mammalian target of rapamycin (mTOR), amyloid-beta, and Tau: effects on cognitive impairments. J. Biol. Chem. 285, 13107-13120 (2010).

21. Imfeld, P., Bodmer, M., Jick, S. S. \& Meier, C. R. Metformin, other antidiabetic drugs, and risk of Alzheimer's disease: a population-based case-control study. J. Am. Geriatr. Soc. 60, 916-921 (2012).

22. Moore, E. M. et al. Increased risk of cognitive impairment in patients with diabetes is associated with metformin. Diabetes. Care. 36, 2981-2987 (2013).

23. Gupta, A., Bisht, B. \& Dey, C. S. Peripheral insulin-sensitizer drug metformin ameliorates neuronal insulin resistance and Alzheimer's-like changes. Neuropharmacology. 60, 910-920 (2011). 
24. Chen, Y. et al. Antidiabetic drug metformin (GlucophageR) increases biogenesis of Alzheimer's amyloid peptides via up-regulating BACE1 transcription Proc Natl Acad Sci U S A. 106, 3907-3912 (2009)

25. Li, J., Deng, J., Sheng, W. \& Zuo, Z. Metformin attenuates Alzheimer's diseaselike neuropathology in obese, leptin-resistant mice. Pharmacol. Biochem. Behav. 101, 564-574 (2012)

26. DiTacchio, K. A., Heinemann, S. F. \& Dziewczapolski, G. Metformin treatment alters memory function in a mouse model of Alzheimer's disease. J. Alzheimers. Dis. 44, 43-48 (2015).

27. Picone, P. et al. Metformin increases APP expression and processing via oxidative stress, mitochondrial dysfunction and NF-kappaB activation: Use of insulin to attenuate metformin's effect. Biochim. Biophys. Acta. 1853, 1046-1059 (2015).

28. Placanica, L., Zhu, L. \& Li, Y. M. Gender- and age-dependent gamma-secretase activity in mouse brain and its implication in sporadic Alzheimer disease. PLoS. ONE. 4, e5088 (2009).
29. Kanashova, T. et al. Differential proteomic analysis of mouse macrophages exposed to adsorbate-loaded heavy fuel oil derived combustion particles using an automated sample-preparation workflow. Anal. Bioanal. Chem. 407, 5965-5976 (2015).

30. Rappsilber, J., Mann, M. \& Ishihama, Y. Protocol for micro-purification, enrichment, pre-fractionation and storage of peptides for proteomics using StageTips. Nat. Protoc. 2, 1896-1906 (2007)

31. Cox, J. \& Mann, M. MaxQuant enables high peptide identification rates, individualized p.p.b.-range mass accuracies and proteome-wide protein quantification. Nat. Biotechnol. 26, 1367-1372 (2008).

32. Bieschke, J. et al. EGCG remodels mature alpha-synuclein and amyloid-beta fibrils and reduces cellular toxicity. Proc Natl Acad Sci U S A. 107, 7710-7715 (2010).

33. Ehrnhoefer, D. E. et al. EGCG redirects amyloidogenic polypeptides into unstructured, off-pathway oligomers. Nat. Struct. Mol. Biol. 15, 558-566 (2008). 